\title{
Membrane remodeling and matrix dispersal intermediates during mammalian acrosomal exocytosis
}

\author{
Miguel Ricardo Leung ${ }^{1,2}$, Ravi Teja Ravi ${ }^{1}$, Bart M. Gadella ${ }^{3}$, and Tzviya Zeev-Ben-Mordehai ${ }^{1,2, *}$ \\ ${ }^{1}$ Bijvoet Centre for Biomolecular Research, Utrecht University, $3584 \mathrm{CH}$ Utrecht, The Netherlands \\ ${ }^{2}$ The Division of Structural Biology, Wellcome Centre for Human Genetics, The University of Oxford, Oxford OX3 7BN, United Kingdom \\ ${ }^{3}$ Department of Farm \& Animal Health and Biomolecular Health Sciences, Faculty of Veterinary Medicine, Utrecht University, 3584 CM Utrecht, The Netherlands \\ *correspondence to: z.zeev@uu.nl
}

\section{Summary}

To become fertilization-competent, mammalian sperm must undergo a complex series of biochemical and morphological changes in the female reproductive tract. These changes, collectively called capacitation, culminate in the exocyto- 50 sis of the acrosome, a large vesicle overlying the nucleus. Acrosomal exocytosis is not an all-or-nothing event, but rather a regulated process in which vesicle cargo disperses gradually. However, the structural mechanisms underlying this controlled release remain undefined. In addition, un- ${ }^{54}$ like other exocytotic events, fusing membranes are shed as 55 vesicles; the cell thus loses the entire anterior two-thirds of 56 its plasma membrane and yet remains intact while the re- 57 maining non-vesiculated plasma membrane becomes fuso- 58 genic. Precisely how cell integrity is maintained throughout this drastic vesiculation process is unclear, as is how it ultimately leads to the acquisition of fusion competence. Here, we use cryo-electron tomography to visualize these processes in unfixed, unstained, fully-hydrated sperm. We show that crystalline structures within the acrosome disassemble during capacitation and acrosomal exocytosis, representing a plausible mechanism for gradual dispersal of the acrosomal matrix. We find that the architecture of the sperm 66 head supports an atypical membrane fission-fusion pathway 67 that maintains cell integrity. Finally, we detail how the acro- 68 some reaction transforms both the micron-scale topography and the nano-scale protein landscape of the sperm surface, thus priming the sperm for fertilization.

sperm | fertilization | acrosome reaction | membrane fusion | cryo-electron 72 tomography physiology and contribute to our understanding of the fundamental yet enigmatic process of mammalian fertilization.

\section{Introduction}

Mammalian sperm must reside in the female reproductive tract for several hours before they are able to fertilize the egg. During this time, sperm undergo a plethora of biochemical changes collectively called capacitation (Aitken and Nixon, 2013; Bailey, 2010; Gervasi and Visconti, 2016). The discovery of this phenomenon was crucial to the development of in vitro fertilization (Austin, 1951; Chang, 1951, 1959). Capacitation is characterized by cholesterol efflux, phospholipase activation, and altered membrane fluidity, along with a multitude of biochemical changes (Bailey, 2010; Harrison and Gadella, 2005; Nolan and Hammerstedt, 1997; Travis and Kopf, 2002). Together, these changes render sperm capable of undergoing the acrosome reaction, a unique exocytotic event that is an absolute requirement for sperm to become fusion-competent (Yanagimachi, 1981) (Fig. 1a).

The acrosome is a large regulated secretory vesicle overlying the anterior two-thirds of the nucleus; its crucial role in mammalian fertilization manifests in the fact that malformation of the acrosome causes infertility in both humans and mice. Three distinct segments of the acrosome can be defined based on their positions along the sperm head (Fig. 1a): the apical segment extends beyond the nucleus and forms the most anterior region of the acrosome; the principal or preequatorial segment forms the major part of the acrosome; and the equatorial segment delimits the posterior part of the acrosome. During acrosomal exocytosis, the plasma membrane fuses with the outer acrosomal membrane at multiple points. This destabilizes the acrosome and liberates its contents, which include several proteins implicated in either penetrating through or binding to the egg vestments (Foster and Gerton, 2016).

Acrosomal exocytosis is not an all-or-nothing event but instead involves the gradual dispersal of vesicle cargo (Hardy et al., 1991; Kim and Gerton, 2003; Kim et al., 2001). Biochemical analyses defined two classes of acrosome contents: a soluble fraction that is released shortly after the onset of the acrosome reaction, and a matrix fraction that disperses more slowly. Consistent with this, conventional electron microscopy (EM) studies showed discrete zones within the acrosome, including crystalline material that extends across large areas of the vesicle in sperm from several mammalian 
species (Fléchon, 2016; Olson and Winfrey, 1994; Phillips, ${ }_{147}$ 1972). However, the structural changes in the acrosomal ma- 148 trix that lead to differential release of acrosome contents are ${ }_{149}$ unclear.

Another distinctive feature of acrosomal exocytosis is the lack of membrane recycling. The plasma membrane and the 152 outer acrosomal membrane are shed as vesicles, so the sperm 153 head loses a large portion of its limiting membrane while the 154 remainder becomes fusogenic. Acrosome vesiculation has 155 been studied extensively with classical EM (Barros et al., 156 1967; Flaherty and Olson, 1991; Jamil and White, 1981; Na- 157 gae et al., 1986; Russell et al., 1979; Sosa et al., 2015; Stock ${ }_{158}$ and Fraser, 1987; Yudin et al., 1988; Zanetti and Mayorga, ${ }_{159}$ 2009), identifying acrosome swelling and membrane dock- ${ }_{160}$ ing as clear intermediates leading to exocytosis (Sosa et al., ${ }_{16}$ 2015; Tsai et al., 2010; Zanetti and Mayorga, 2009), However, the membrane remodeling pathways that ensure the cell ${ }_{163}$ remains intact throughout this dramatic vesiculation process ${ }_{164}$ remain undefined.

Here, we use cryo-electron tomography (cryo-ET) to im- ${ }_{166}$ age sperm undergoing in vitro capacitation and acrosome ex- ${ }_{167}$ ocytosis. Cryo-ET provides three-dimensional information ${ }_{168}$ about rare events in unfixed, unstained, fully-hydrated sam- ${ }_{169}$ ples, and thus in close to native conditions ( $\mathrm{Ng}$ and Gan, ${ }_{170}$ 2020). We show that the crystalline component of the acro- ${ }_{171}$ somal matrix gradually dissolves during acrosomal exocytosis, explaining the differential release previously observed. We also find that the defined ultrastructural organization of ${ }_{174}$ the sperm head facilitates a unique fission-fusion mechanism that maintains cell integrity despite drastic membrane vesiculation. We demonstrate that acrosome exocytosis also facilitates massive membrane protein re-localization onto the post-acrosomal plasma membrane, building a platform for interaction with the egg.

\section{Results}

In unstimulated sperm, the plasma membrane (PM) ${ }^{183}$ and the outer acrosomal membrane (OAM) are closely ${ }^{184}$ apposed along the entire acrosome. We plunge-froze ${ }^{185}$ sperm from highly fertile, commercial artificial insemination ${ }^{186}$ pigs (Sus scrofa domestica) and imaged them using cryo-ET. ${ }^{187}$ In intact unstimulated sperm, the plasma membrane (PM) and ${ }^{188}$ the outer acrosomal membrane (OAM) are closely apposed ${ }^{189}$ along the entire acrosome (Fig. 1b,c; Fig. S1). The PM and ${ }^{190}$ the OAM are $\sim 8-10 \mathrm{~nm}$ apart and lie parallel to each other ${ }^{191}$ until the equatorial segment of the acrosome, where the vesi- 192 cle tapers (Fig. S1d-f). This differs from many classical EM ${ }^{193}$ images of unstimulated sperm, in which the PM and OAM ${ }^{194}$ appear wavy with estimated interbilayer distances of $>10 \mathrm{~nm}^{195}$ (Sosa et al., 2015; Tsai et al., 2010; Zanetti and Mayorga, ${ }^{196}$ 2009), and demonstrates the benefits of using cryo-ET to vi- ${ }^{197}$ sualise acrosomal exocytosis.

The crystalline fraction of the acrosomal matrix pro- 200 gressively disassembles during exocytosis. We sought 201 to determine how the internal organization of the acrosome 202 changes during acrosomal exocytosis. We first imaged acro- 203 some contents in intact unstimulated sperm cells thinned to 150-200 nm with cryo-focused ion beam (cryo-FIB) milling (Marko et al., 2006; Rigort et al., 2012). Even after thinning and imaging with the Volta phase plate (VPP) (Danev et al., 2014; Fukuda et al., 2015), the acrosome lumen was still very dense (Fig. 1b,c). Nonetheless, we observed large patches of crystalline material in both the apical and pre-equatorial regions of the acrosome (insets in Fig. 1b,c), similar to the structures observed in rat sperm (Phillips, 1972), rabbit sperm (Olson and Winfrey, 1994), and ram sperm (Fléchon, 2016).

To visualise acrosomal exocytosis, we imaged sperm incubated in capacitating media (containing calcium, bicarbonate, and bovine serum albumin) for $\sim 2 \mathrm{~h}$ and subsequently treated with calcium ionophore A23187 (Fig. S2) or progesterone for up to $30 \mathrm{~min}$. Following treatment, fully acrosomereacted sperm could be readily targeted in low-magnification cryo-EM projection images (Fig. S3). These cells were surrounded by a cloud of vesicles (the acrosomal shroud) (Fig. S3a) and their apical regions had become very thin due to the loss of the acrosome (Fig. S3b), allowing us to image them without cryo-FIB milling. We note that acrosomal shrouds tend to remain associated with sperm heads despite several pipetting and dilution steps before imaging. In our analyses, we excluded sperm in which the plasma membrane peeled off at the equatorial/post-acrosomal regions, which would likely result in loss of cell integrity and thus in cell death (Fig. S3cd).

We found that the acrosomal shroud consists of a highly heterogeneous population of vesicles that are decorated with membrane proteins (Fig. 1e,f). Interspersed between these vesicles are the contents of the acrosome, including striking crystalloid patches that were heterogeneous in both size and shape (Fig. 1e; Fig. S4a,b) (ionophore: 12/13 tomograms, each from a different cell, from 3 different animals; progesterone: 5/5 tomograms, each from a different cell, from 1 animal).

To follow the crystalloids during intermediate stages of exocytosis, we imaged cells incubated in capacitating media without ionophore treatment. Crystalloids were readily visible in swollen acrosomes (Fig. 1d), where they had already begun to dissociate into smaller fragments. We then used subtomogram averaging to resolve the structure of the crystalloid patches at a resolution of $\sim 30-40 \AA$ (Fig. 2). We chose to average from capacitated sperm since the surrounding material was too dense in naïve sperm. The patches were also larger in capacitated sperm than in the shrouds of acrosomereacted sperm, which facilitated averaging by increasing particle numbers. Our averages reveal that the crystalloids adopt a tetragonal body-centered crystal lattice with apparent unit cell dimensions $\mathrm{a}=28 \mathrm{~nm}, \mathrm{~b}=28 \mathrm{~nm}, \mathrm{c}=40 \mathrm{~nm}$.

Taken together, our data indicate that the crystalloids in the acrosomal shroud result from disassembly of an initial larger superstructure. These crystalloids may thus represent the core of the acrosomal matrix, acting as a structural scaffold onto which soluble components of the acrosome are anchored. Their progressive disassembly may represent a 
bioRxiv preprint doi: https://doi.org/10.1101/2021.08.04.455016; this version posted August 5, 2021. The copyright holder for this preprint (which was not certified by peer review) is the author/funder, who has granted bioRxiv a license to display the preprint in perpetuity. It is made available under aCC-BY-NC-ND 4.0 International license.

a
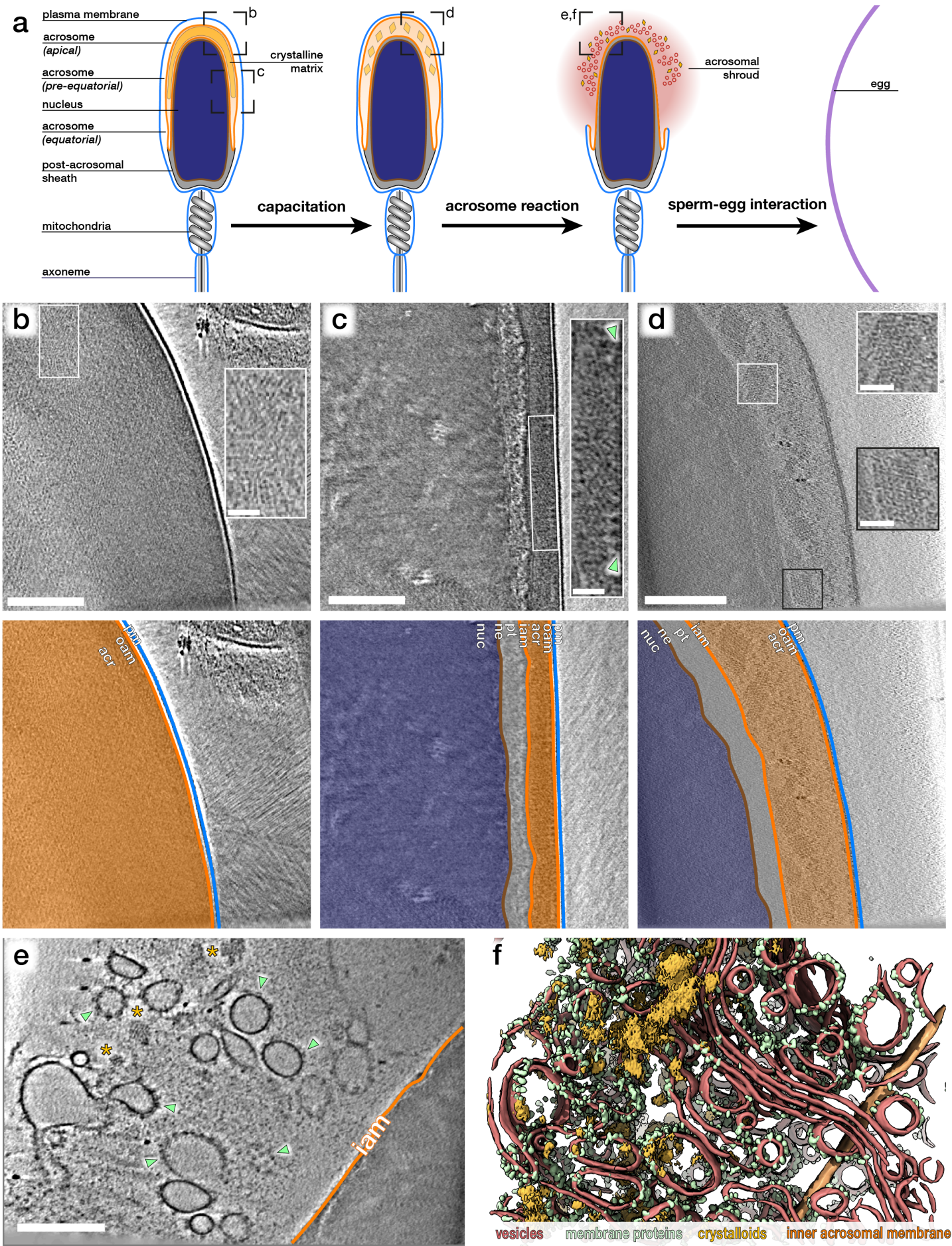

Fig. 1. The crystalline fraction of the acrosomal matrix progressively disassembles during acrosomal exocytosis. (a) Schematic diagram illustrating the morphological changes that mammalian sperm undergo in the female reproductive tract, simulated in this study in vitro. (b-c) Computational slices through Volta phase plate cryo-tomograms of non-capacitated sperm thinned by cryo-focused ion beam milling. Note how the acrosome is dense even in thinned samples. Insets show regions with large crystalloid patches. Large membrane protein densities are visible on the luminal surface of the outer acrosomal membrane (green arrowheads in inset). (d) Computational slice through a defocus-contrast cryo-tomogram of a sperm cell whose acrosome had swollen after incubation in capacitating media for $\sim 2 \mathrm{~h}$. Note decondensation of the acrosome and prominent crystalloid patches (insets). (e-f) Computational slice (e) and corresponding three-dimensional segmentation (f) of the acrosomal shroud. The cell was incubated in capacitatng media for $\sim 2 \mathrm{~h}$ and treated with calcium ionophore for $\sim 30 \mathrm{~min}$. Note crystalloid patches (asterisks in e, goldenrod in $\mathrm{f}$ ) and membrane proteindecorated vesicles (green arrowheads in e, green in f). Scale bars: $250 \mathrm{~nm}$; insets: $50 \mathrm{~nm}$. Color scheme: orange - outer and inner acrosomal membrane, red - vesiculated plasma and outer acrosomal membranes, green - membrane protein densities, goldenrod crystalloid patches 

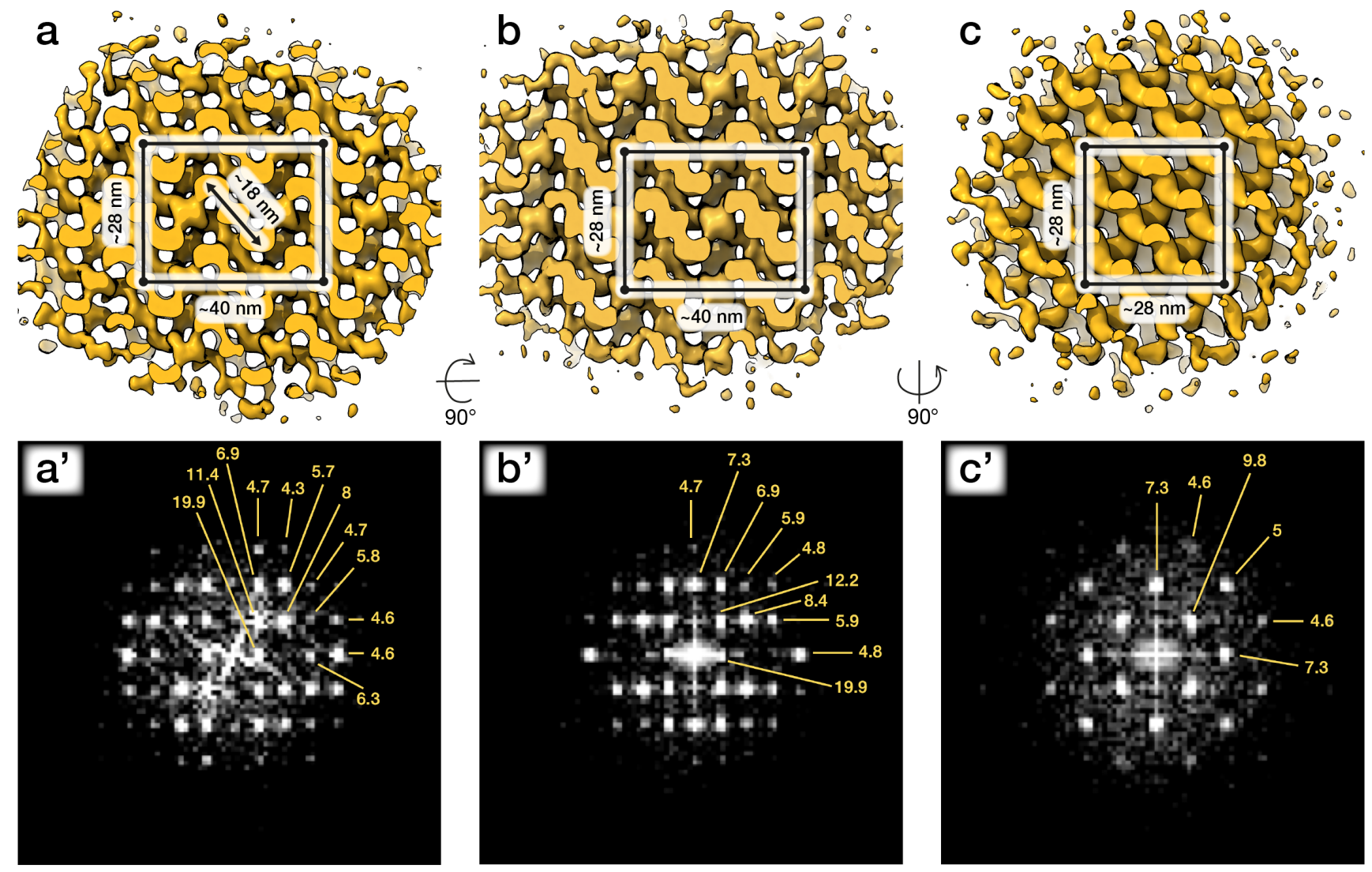

Fig. 2. In situ structures of crystalloid patches from capacitated sperm. Three orthogonal isosurface views (a-c) and corresponding Fourier transforms (a'-c') of a subtomogram average of $40 \times 40 \times 40 \mathrm{~nm}$ crystalloid patch from swollen acrosomes of boar sperm incubated in capacitating media for $\sim 2 \mathrm{~h}$. The putative tetragonal body-centered unit cell is annotated in (a-c). Averages were generated from $\sim 1400$ particles from two cells.

mechanism for controlled release of acrosome contents that 228 appears to be conserved across mammals.

An atypical membrane fission-fusion pathway maintains cell integrity at the equatorial segment. We then ${ }_{232}$ sought to trace membrane remodelling intermediates in- 233 volved in capacitation and acrosomal exocytosis. Sperm ${ }_{234}$ within an ejaculate are inherently variable (Buffone et al., 235 2014), which precludes a strictly timepoint-based assess- 236 ment of the reaction coordinate. We instead imaged sev- ${ }_{237}$ eral cells from several different animals (Table S1), analysed the dataset for membrane remodelling intermediates that we 238 could observe consistently, and ordered these stages relative 239 to one another (Fig. 3, Fig. 4).

We captured a range of intermediates already in capaci- 241 tated sperm without ionophore stimulation (Fig. 3), includ- 242 ing acrosome swelling, membrane docking, and membrane ${ }_{243}$ destabilization (Fig. S5). Acrosome swelling is one of the 244 earliest stages of acrosomal exocytosis (Sosa et al., 2015; 245 Zanetti and Mayorga, 2009), and indeed was observed even 246 in capacitated cells (Boerke et al., 2014). Swelling is associ- 247 ated with decondensation of acrosomal contents, but our to- 248 mograms reveal that decondensation is not uniform. Specif- 249 ically, a dense core remains near the center of the vesicle ${ }_{250}$ (white arrowhead in Fig. 3b), which is continuous with a 25 thin streak of electron-dense material sandwiched between the OAM and the IAM at the end of the acrosome (white arrowhead in Fig. 4b). Decondensation also improves contrast in the acrosome, making visible large membrane protein densities on the luminal surface of the OAM (green arrowhead in Fig. 3b,c). These structures are also visible in VPP tomograms of FIB-milled unstimulated sperm (green arrowheads in Fig. 1b inset and Fig. 3a). The OAM proteins form rows of teeth-like densities, each extending $\sim 14 \mathrm{~nm}$ into the OAM lumen and spaced $\sim 18 \mathrm{~nm}$ from its neighbours.

We could further distinguish between two stages of acrosome swelling: one in which the acrosome swells but the overlying membranes are still intact (Fig. 3b,e), and another in which the OAM already destabilizes (Fig. 3c,f). OAM destabilization is characterised by local membrane rupture (Fig. 3c,f; Fig. 4c; Fig. S5g-1). OAM rupture was associated with the extent of acrosome swelling; in cells with ruptured OAMs, the acrosome had swollen to nearly twice its original width $(136 \pm 24 \mathrm{~nm}$ versus $71 \pm 11 \mathrm{~nm}$, with an intermediate value of $100 \pm 18 \mathrm{~nm}$ in cells with swollen acrosomes but intact membranes) (Fig. 3g). In contrast, the width of the equatorial segment did not change significantly even in cells with ruptured OAMs (acrosome swollen, membranes destabilized: $38 \pm 2 \mathrm{~nm}$; acrosome swollen, membranes intact: 38 
bioRxiv preprint doi: https://doi.org/10.1101/2021.08.04.455016; this version posted August 5, 2021. The copyright holder for this preprint (which was not certified by peer review) is the author/funder, who has granted bioRxiv a license to display the preprint in perpetuity. It is made available under aCC-BY-NC-ND 4.0 International license.

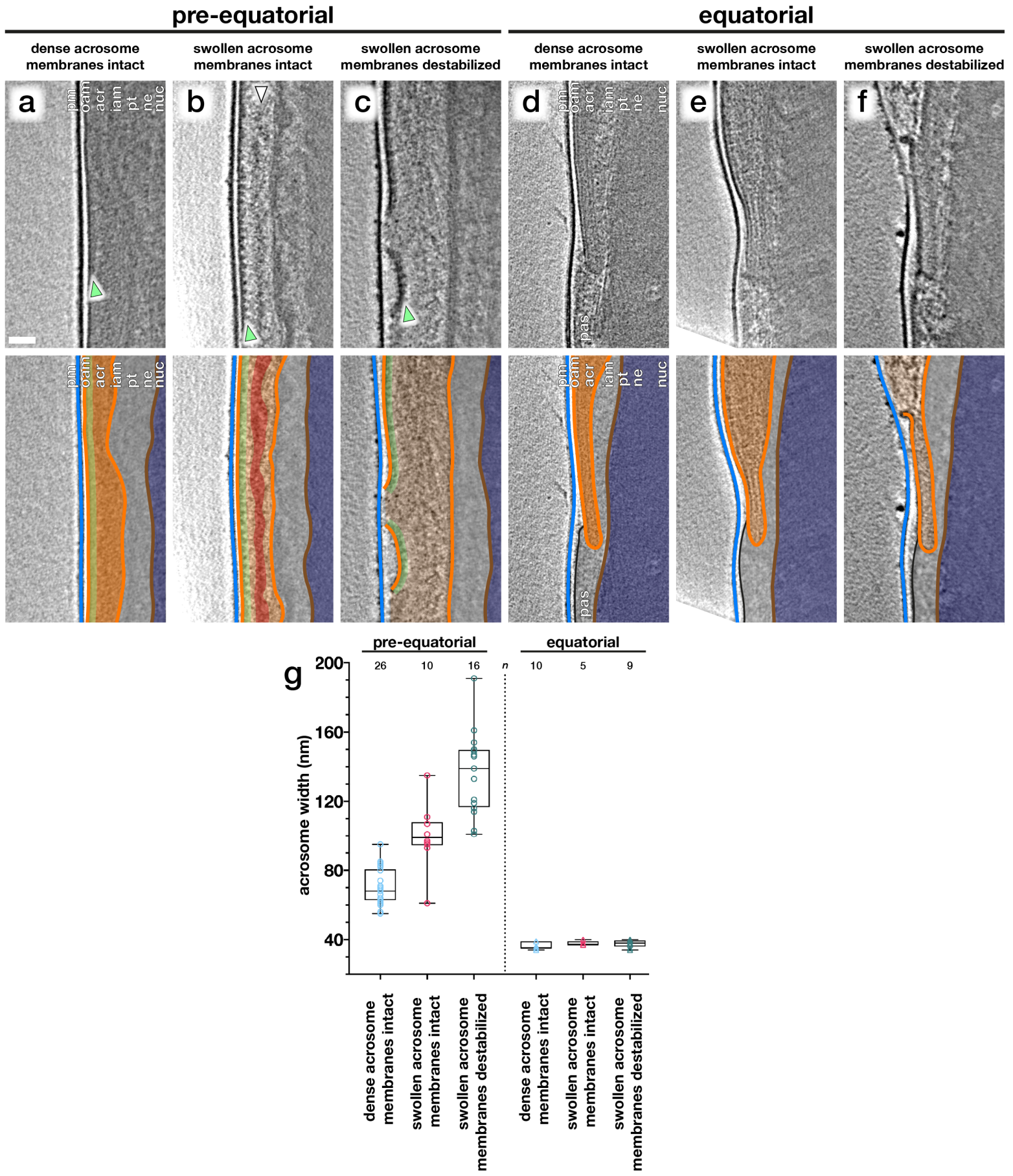

Fig. 3. Acrosome swelling is associated with membrane destabilization in capacitated sperm. (a-f) Computational slices (top panels) and schematic annotations (bottom panels) of Volta phase plate cryo-tomograms of the pre-equatorial (a-c) and equatorial (d-f) region of sperm before ( $a, d)$ or after (b-c, e-f) a $\sim 2 \mathrm{~h}$ incubation in capacitating media without ionophore stimulation. Note the rows of membrane protein densities on the outer acrosomal membrane (green arrowheads in a-c) and the streak of acrosomal matrix that remains condensed during acrosome swelling (white arrowhead in b). (g) Measurements of acrosomal width at the pre-equatorial (left) and equatorial (right) regions in sperm showing various states of acrosome swelling and membrane destabilization. For each tomogram, acrosome width was measured as the distance between the outer and inner acrosomal membranes at three different locations. Each tomogram is from a different cell ( $n$ indicates the number of tomograms used for analysis). The boxes indicate the median and interquartile range, while the whiskers indicate the minimum and maximum values. Scale bar: $50 \mathrm{~nm}$. Labels: pm plasma membrane, oam - outer acrosomal membrane, acr - acrosome, iam - inner acrosomal membrane, pt - perinuclear theca, ne - nuclear envelope, nuc - nucleus, pas - post-acrosomal sheath. Color scheme: blue - plasma membrane, orange - outer and inner acrosomal membranes, green - membrane protein densities, red - condensed acrosomal material, light grey - perinuclear theca and post-acrosomal sheath, brown - nuclear envelope, dark blue - nucleus 
$\pm 1 \mathrm{~nm}$; dense acrosome, membranes intact: $36 \pm 2 \mathrm{~nm}$ ). No- ${ }_{309}$ tably, OAM rupture occurred just anterior to the equatorial segment, on average $260 \pm 80 \mathrm{~nm}$ from the end of the acrosome (mean \pm s.d., 8 tomograms, each from a different cell) ${ }^{311}$ (Fig. 3f).

Focusing on the equatorial segment, we observed an atypi- ${ }^{313}$ cal membrane fission-fusion pathway that mediates resealing ${ }^{314}$ of the sperm head (Fig. 4). The ruptured end of the OAM fuses with the overlying PM (Fig. 4c,d; Fig. S5j-l) and after ${ }^{31}$ this fusion event, the electron-dense streak also diffuses, leav- ${ }^{31}$ ing a hairpin-shaped membrane (Fig. 4e, Fig. S6a-b). This ${ }^{31}$ hairpin-shaped membrane then constricts and buds off just ${ }^{31}$ anterior to the post-acrosomal sheath (Fig. 4e, arrowhead), yielding the characteristic morphology of acrosome-reacted cells (Fig. 4f, Fig. S6c).

Acrosomal exocytosis transforms the molecular land- 32 scape of the sperm plasma membrane. After loss of the ${ }^{325}$ acrosome, the inner acrosomal membrane (IAM) is the new ${ }^{326}$ limiting membrane of the apical segment of the sperm cell ${ }^{327}$ (Fig. 1e). The PM overlying the equatorial/post-acrosomal ${ }^{328}$ segment remains intact and is now continuous with the IAM ${ }^{329}$ (Fig. 5). Segmentation of high-contrast tomograms acquired ${ }^{330}$ with a VPP revealed that the PM forms a "sheath" around ${ }^{33}$ the post-acrosomal region (Fig. 5d, Fig. S6). Our tomo- ${ }^{332}$ grams also showed tubulovesicular projections overlying the ${ }^{33}$ equatorial segment (Fig. 5d, Fig. S6). These tubular mem- ${ }^{334}$ branes are consistent with those observed by freeze-fracture ${ }^{335}$ EM (Aguas and da Silva, 1989). Thus, the acrosome reaction ${ }^{336}$ remodels the overall topography of the sperm surface.

We then compared the post-acrosomal segment in naïve ${ }^{338}$ versus acrosome-reacted sperm (Fig. 5b,e; Fig. S7). In- 339 specting the PM overlying the post-acrosomal sheath reveals ${ }^{340}$ major differences in protein decoration. In unreacted cells, ${ }^{341}$ the post-acrosomal PM is relatively smooth, with only a few ${ }^{342}$ small protein densities protruding from the membrane (Fig. ${ }^{343}$ 5b, Fig. S7a-c) (14/14 tomograms, each from a different cell, ${ }^{344}$ from 6 different animals). In contrast, the post-acrosomal ${ }^{345}$ PM was densely packed with membrane protein densities in $\sim 80 \%$ of tomograms of acrosome-reacted cells (30/37 tomo- 346 grams, each from a different cell, from 5 different animals) ${ }_{347}$ (Fig. 5e,g; Fig. S7d-f). These densities do not appear to be ${ }_{34}$ ordered, which suggests that they represent a range of differ- 349 ent conformations, proteins, or protein complexes. Thus, the ${ }_{350}$ acrosome reaction results in massive membrane protein re- 351 localization that alters the molecular landscape of the sperm 352 surface.

We then used subtomogram averaging to define the sub- 354 structure of the post-acrosomal sheath in more detail (Fig. 355

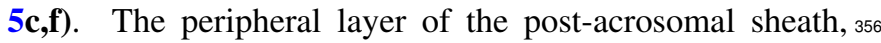
immediately underlying the PM, consists of a multi-layered ${ }_{357}$ structure with an $\sim 8-\mathrm{nm}$ repeating unit. Our averages reveal 358 that neither the substructure nor the overall organization of 359 the post-acrosomal sheath change noticeably after acrosomal 360 exocytosis, which is consistent with measurements directly ${ }_{361}$ from tomograms (Fig. 5h). Similarly, the distance between ${ }_{362}$ the PM and the post-acrosomal sheath remains relatively un- 363 changed (unreacted: $15 \pm 2 \mathrm{~nm}$, reacted: $18 \pm 3 \mathrm{~nm}$ ).

\section{Discussion}

Gradual disassembly of the crystalline matrix may represent a mechanism for controlled release of acrosome contents. Leading up to and during acrosomal exocytosis, acrosome contents disperse at rates dependent on their partitioning into either soluble or particulate fractions. The particulate fraction, also known as the acrosomal matrix, disperses gradually in a process dependent on alkalization and proteolytic self-digestion (Buffone et al., 2008). However, we do not understand the underlying structural transitions in the acrosomal matrix that regulate the dispersal of acrosomal contents. Studies of acrosomal matrix dispersal are often performed on guinea pig sperm, which have large acrosomes partitioned into subdomains easily visible by transmission EM (Flaherty and Olson, 1988; Hardy et al., 1991; Kim et al., 2001; Olson and Winfrey, 1994). Here, we use cryo-ET to show that the acrosome is structurally compartmentalized also in boar sperm (Fig. 1), which have comparatively thin acrosomes and no obvious subdomains when viewed by conventional EM (Buffone et al., 2008).

Specifically, we find an extensive crystalline fraction in the boar sperm acrosome. Although crystalline structures have been demonstrated previously in acrosomes of other mammals, they were not followed throughout capacitation and acrosomal exocytosis. Our data now show that the crystalline fraction begins to disassemble during capacitation (Fig. 1d) and continues to do so during acrosomal exocytosis, resulting in small patches scattered amongst the vesicles of the acrosomal shroud (Fig. 1e,f). Gradual disassembly of the crystalline matrix thus represents a plausible mechanism for controlled release of acrosome contents. Refining this model will require further studies aimed at determining the nature of the crystalline fraction - for instance, whether it represents a scaffolding structure or a storage phase for inactive enzymes. The subtomogram averages we present here (Fig. 2) can help towards this goal by providing constraints on the molecular dimensions of candidate proteins.

Cryo-ET reveals how capacitation-associated membrane destabilization relates to the membrane fission-fusion processes involved in acrosomal exocytosis. Our observations suggest that acrosome swelling relates directly to membrane destabilization (Fig. 3), which is likely caused by an increase in membrane tension in addition to known changes in membrane composition mediated by cholesterol efflux and phospholipase activation (Aitken and Nixon, 2013; Asano et al., 2013). A role for swellingdependent membrane destabilization is also supported by observations that hyper-osmotic conditions inhibit the acrosome reaction (Bielfeld et al., 1993) and that lysophosphatidylcholine, a positive curvature amphiphile that reduces the energetic barrier for membrane rupture (Glushakova et al., 2005), promotes the reaction (de Lamirande et al., 1997; Parrish et al., 1988). Meanwhile, the equatorial region is stabilized by the electron-dense core of the acrosome (Fig. 3df) and the post-acrosomal region likewise stabilized by the post-acrosomal sheath. Thus, the precise organization of the 

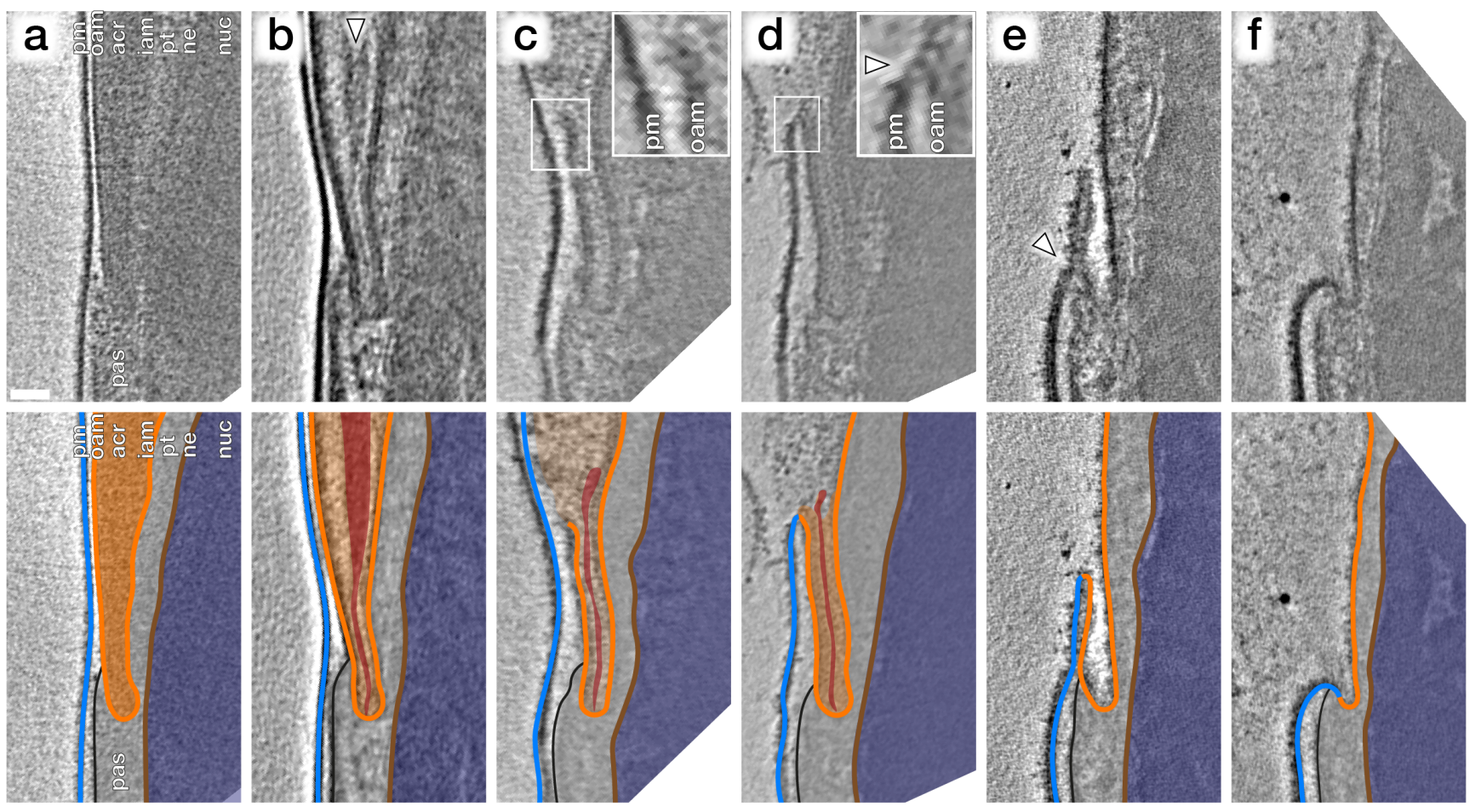

Fig. 4. An atypical membrane fission-fusion pathway maintains cell integrity at the equatorial region. (a-f) Computational slices (top panels) and corresponding schematic annotations (bottom panels) of Volta phase plate cryo-tomograms of the equatorial region of boar sperm incubated for $\sim 2 \mathrm{~h}$ in capacitating media without (a-d) and with (e-f) subsequent $\sim 30$ min ionophore stimulation. In (b), the white arrowhead indicates condensed material at the core of the acrosome that is continuous with a thin streak of electron-dense material in the equatorial segment. In (c), the inset shows the point of OAM rupture immediately anterior to the equatorial region. In (d), the inset shows that the OAM has fused (white arrowhead) with the overlying PM at this location. Scale bar: $50 \mathrm{~nm}$. Labels: pm plasma membrane, oam - outer acrosomal membrane, acr - acrosome, iam - inner acrosomal membrane, pt - perinuclear theca, ne - nuclear envelope, nuc - nucleus, pas - post-acrosomal sheath' Color scheme: blue - plasma membrane, orange - outer and inner acrosomal membranes, light grey - perinuclear theca and post-acrosomal sheath, brown - nuclear envelope, dark blue - nucleus

sperm head facilitates the rupture-fusion pathway that main- $з 88$ tains cell integrity despite destabilization and vesiculation of 389 the rest of the acrosome (Fig. 4).

The intermediates we observe do not appear to fit the 391 canonical fusion-by-hemifusion pathway; instead, the pres- 392 ence of membrane edges is reminiscent of the rupture- 393 insertion pathway (Chlanda et al., 2016; Haldar et al., 2019). 394 Whether fusion proceeds via hemifusion or via rupture- 395 insertion depends on membrane spontaneous curvature and ${ }_{396}$ hence on lipid composition, with the rupture-insertion path- 397 way strongly favoring cholesterol-poor bilayers (Chlanda et ${ }_{398}$ al., 2016; Haldar et al., 2019). This may be particularly rel- 399 evant given that one of the molecular signatures of capacita- 400 tion is cholesterol efflux.

Acrosomal exocytosis transforms the molecular land- 403 scape of the sperm plasma membrane. Acrosomal exo- 404 cytosis is an absolute requirement for mammalian sperm to 405 fuse with the egg (Yanagimachi, 1981). Fluorescence mi- 406 croscopy has shown that as a result of the acrosome reac- 407 tion, Izumo1 re-localizes onto the plasma membrane, allow- 408 ing it to interact with its oocyte-borne partner, Juno, to medi- 409 ate sperm-egg adhesion (Satouh et al., 2012). However, the 410 Izumo1-Juno interaction is not sufficient to mediate mem- 411 brane fusion (Bianchi et al., 2014). Our understanding of sperm-egg fusion is hampered by the fact that, beyond the translocation of Izumo1, we know very little about what happens to the molecular landscape of the sperm surface after the acrosome reaction.

Here, we show that acrosomal exocytosis transforms both the micron-scale topography and the molecular landscape of the sperm surface (Fig. 5). We find that the post-acrosomal plasma membrane becomes heavily decorated with membrane protein densities. Such changes may be due to the re-localization of membrane proteins, similar to the phenomenon observed by freeze-fracture EM for the acrosomal cap region (Aguas and da Silva, 1989), or to the binding of liberated acrosomal proteins to pre-existing receptors. The post-acrosomal membrane protein densities do not appear to be ordered, which suggests that they represent a range of different conformations, proteins, or protein complexes. Indeed, in addition to Izumo1, there are now a number of proteins on mammalian sperm that are known to be essential for spermegg binding and fusion (Fujihara et al., 2020; Inoue et al., 2005; Lamas-Toranzo et al., 2020; Noda et al., 2020). Our results therefore complement the emerging view that mammalian sperm-egg fusion involves several molecular species acting in concert. Our work also opens avenues for future 
not reacted
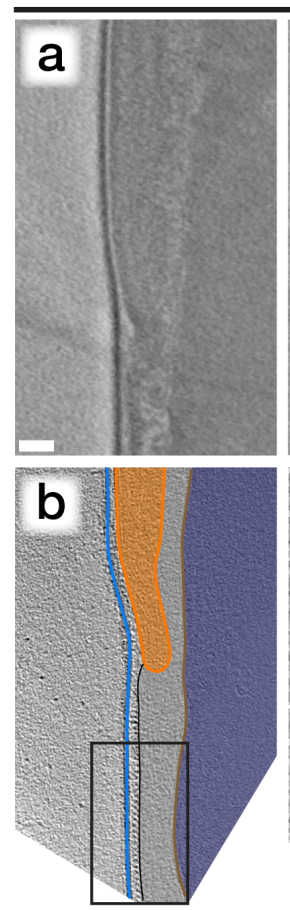
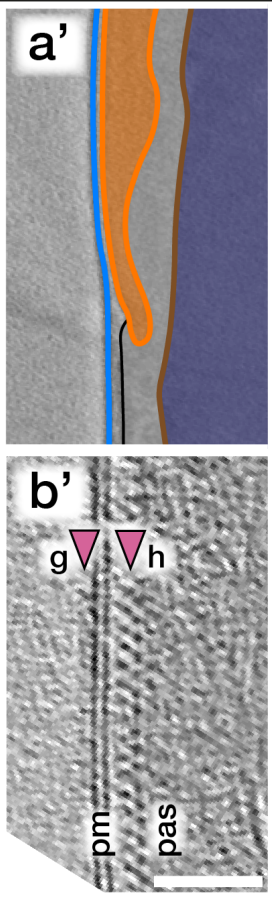

$a^{\prime \prime}$
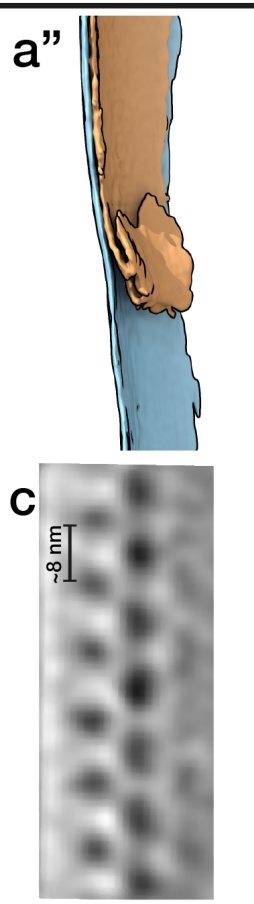

acrosome-reacted
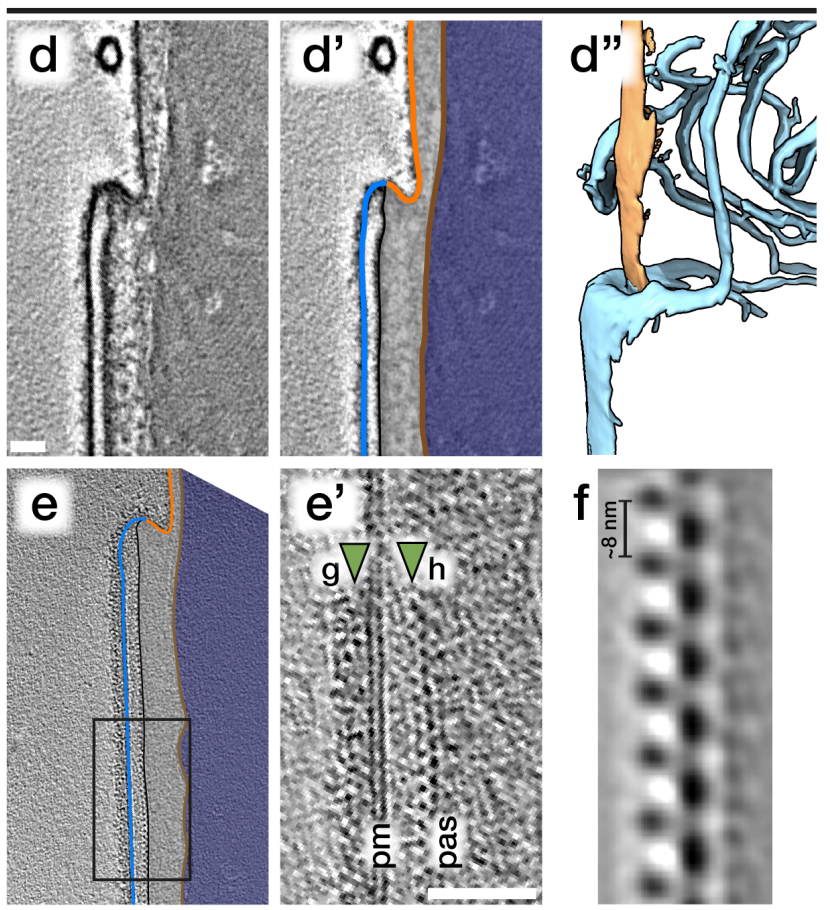
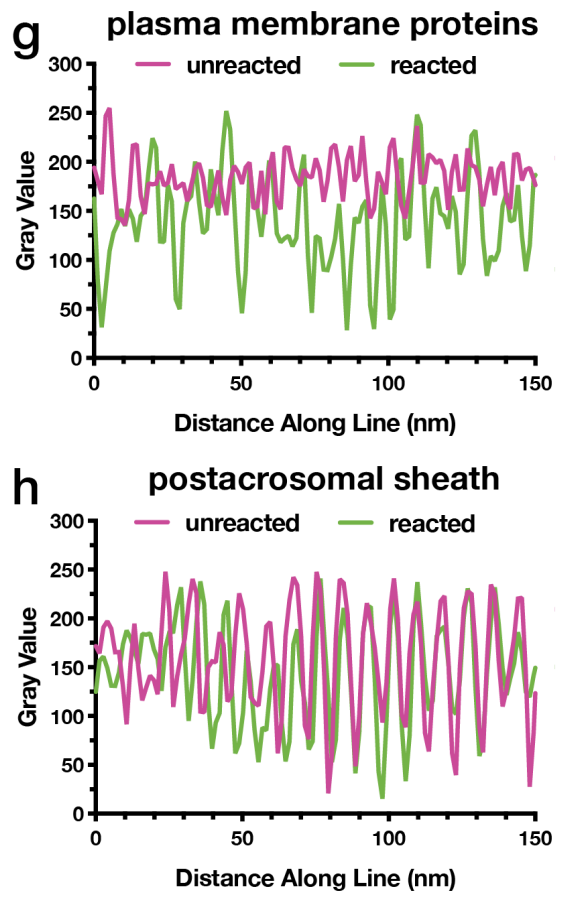

Fig. 5. Acrosomal exocytosis transforms the molecular landscape of the sperm plasma membrane. Comparing the postacrosomal plasma membrane in unreacted (a-c) versus acrosome-reacted (d-f) reveals major differences in membrane protein decoration. (a,d) Computational slices (a \& a', d \& d') and corresponding segmentations (a", d") of VPP cryo-tomograms illustrating how acrosomal exocytosis remodels the topography of the equatorial region. (b,e) Computational slices through defocus-contrast cryotomograms illustrating how the post-acrosomal plasma membrane becomes densely-packed with membrane proteins after acrosomal exocytosis. (c,f) Subtomogram averages of the post-acrosomal sheath from unreacted (c) and acrosome-reacted (f) cells. (g,h) Exemplary linescans illustrating changes in membrane protein density after the acrosome reaction (g), as well as the lack of noticeable change in the post-acrosomal sheath (h). Linescans were taken at the approximate locations marked by arrowheads in (b') and (e'). Scale bars: $50 \mathrm{~nm}$. Labels: pm - plasma membrane, pas - post-acrosomal sheath. Color scheme: blue - plasma membrane, orange - outer and inner acrosomal membranes, light grey - perinuclear theca and post-acrosomal sheath, brown - nuclear envelope, dark blue - nucleus 
work into how these various players are organized on the 462 sperm membrane at the nano-scale.

\section{Acknowledgements}

The authors thank Dr. M Vanevic for excellent compu- ${ }_{467}$ tational support, and Dr. SC Howes, Ingr. CTWM Schnei- ${ }_{468}$ jdenberg \& JD Meeldijk for managing and maintaining the ${ }_{469}$ Utrecht University EM Square facility. The authors also 470 thank S Leemans and L Teeuwen for their help with sperm ${ }_{471}$ preparation in initial stages of the project. The authors also 472 thank the Henriques Lab for the publicly-available $\mathrm{LAT}_{\mathrm{E}} \mathrm{X}_{473}$ template. This work benefitted from access to the Nether- ${ }^{474}$ lands Center for Electron Nanoscopy (NeCEN) with support from operators Dr. RS Dillard and Dr. CA Diebolder and IT 475 support from B Alewijnse. This work was funded by NWO 476 Start-Up Grant 740.018.007 to TZ, and MRL is supported 477 by a Clarendon Fund-Nuffield Department of Medicine Prize 478 Studentship.

\section{Author Contributions}

MRL and RTR prepared samples for cryo-EM. MRL, ${ }_{483}$ RTR, and TZ collected and analyzed cryo-ET data. MRL, ${ }_{484}$ RTR, BMG, and TZ wrote the manuscript.

\section{Declaration of Interests}

The authors declare no competing interests.

\section{Materials and Methods}

Sperm washing, capacitation, and acrosome reac- 492 tion. Freshly-ejaculated pig (Sus scrofa domestica) semen $_{493}$ was purchased from an artificial insemination company ${ }_{494}$ (AIM Varkens KI Nederland). Semen was typically di- ${ }_{495}$ luted in Beltsville's thawing solution (BTS: $205 \mathrm{mM}$ glucose, ${ }_{496}$ $20 \mathrm{mM} \mathrm{NaCl}, 5 \mathrm{mM} \mathrm{KCl}, 15 \mathrm{mM} \mathrm{NaHCO}_{3}, 3 \mathrm{mM}$ EDTA) ${ }_{497}$ and stored at $18^{\circ} \mathrm{C}$ until use. Sperm were used within 1 day ${ }_{498}$ of delivery. Sperm were gently layered onto a discontin- ${ }_{499}$ uous gradient consisting of $2 \mathrm{~mL}$ of $70 \%$ Percoll overlaid ${ }_{500}$ with $4 \mathrm{~mL}$ of $30 \%$ Percoll, both in HEPES-buffered saline ${ }_{501}$ (HBS: $20 \mathrm{mM}$ HEPES, $137 \mathrm{mM} \mathrm{NaCl}, 10 \mathrm{mM}$ glucose, $2.5 \mathrm{mM} \mathrm{KCl}, 0.1 \%$ kanamycin, $\mathrm{pH}$ 7.6) and centrifuged ${ }_{502}$ at $750 \mathrm{~g}$ for $15 \mathrm{~min}$. Pelleted cells were washed once in ${ }_{503}$ phosphate-buffered saline (PBS: $137 \mathrm{mM} \mathrm{NaCl}, 3 \mathrm{mM} \mathrm{KCl}, 504$ $8 \mathrm{mM} \mathrm{Na}_{2} \mathrm{HPO}_{4}, 1.5 \mathrm{mM} \mathrm{KH}_{2} \mathrm{PO}_{4}, \mathrm{pH}$ 7.4), resuspended in 505 PBS, and counted.

Washed sperm were resuspended in 1X TALP ${ }_{507}$ (20 mM HEPES, $90 \mathrm{mM} \mathrm{NaCl}, 21.7 \mathrm{mM}$ sodium lac- 508 tate, $15 \mathrm{mM} \mathrm{NaHCO}$, $5 \mathrm{mM}$ glucose, $3.1 \mathrm{mM} \mathrm{KCl,} 509$ $2 \mathrm{mM} \mathrm{CaCl}_{2}, 1 \mathrm{mM}$ sodium pyruvate, $0.4 \mathrm{mM} \mathrm{MgSO}_{4},{ }_{510}$ $0.3 \mathrm{mM} \mathrm{NaH} \mathrm{PO}_{4}, 100 \mu \mathrm{g} / \mathrm{mL}$ kanamycin, $0.3 \% \mathrm{w} / \mathrm{v}$ fatty 511 acid-free BSA (Sigma), pH 7.4) at $\sim 10-20 \times 10^{6}$ cells $/ \mathrm{mL} .512$ Sperm were allowed to capacitate for between 2 and $2.5_{513}$ hours at $37^{\circ} \mathrm{C}, 5 \% \mathrm{CO}_{2}$. In order to stimulate the acrosome ${ }_{514}$ reaction more rapidly and in a larger percentage of cells, 515 either calcium ionophore A23187 (Sigma) or progesterone 516
(Sigma) was added to capacitated cells to a final concentration of either $5 \mu \mathrm{M}$ or $3 \mu \mathrm{M}$, respectively. Cells were incubated for a further $30 \mathrm{~min}$ (for ionophore) or $1 \mathrm{~h}$ (for progesterone) at $37^{\circ} \mathrm{C}, 5 \% \mathrm{CO}_{2}$.

For flow cytometry, cells were first washed with PBS and their concentration adjusted to $30-50 \times 10^{6}$ cells $/ \mathrm{mL}$. Sperm were then stained with propidium iodide (PI) (LifeTechnologies) and with PNA-fluorescein isothiocyanate (FITC)(Sigma), both at a final concentration of $1 \mu \mathrm{g} / \mathrm{mL}$. Sperm were then diluted $1 / 100$ to $0.5 \times 10^{6}$ cells $/ \mathrm{mL}$ and analyzed using a BD FACSCanto II flow cytometer. Viable, acrosome-reacted cells were defined as those in the $\mathrm{PI}^{+} \mathrm{FITC}^{+}$ quadrant of the cytogram.

Cryo-EM grid preparation. Typically, $3 \mu \mathrm{L}$ of a suspension containing either $2-3 \times 10^{6}$ cells $/ \mathrm{mL}$ (for whole cell tomography) or $20-30 \times 10^{6}$ cells/mL (for cryo-FIB milling) was pipetted onto a glow-discharged Quantifoil R 2/1 200mesh holey carbon grid. One $\mu \mathrm{L}$ of a suspension of BSAconjugated gold beads (Aurion) was added, and the grids then blotted manually from the back (opposite the side of cell deposition) for $\sim 3 \mathrm{~s}$ (for whole cell tomography) or for $\sim 5-6 \mathrm{~s}$ (for cryo-FIB milling) using a manual plunge-freezer (MPI Martinsreid). Grids were immediately plunged into a liquid ethane-propane mix (37\% ethane) (Tivol et al., 2008) cooled to liquid nitrogen temperature. Grids were stored under liquid nitrogen until imaging.

Cryo-focused ion beam milling. Grids were mounted into modified Autogrids (ThermoFisher) for mechanical support. Clipped grids were loaded into an Aquilos (ThermoFisher) dual-beam cryo-focused ion beam/scanning electron microscope (cryo-FIB/SEM). All SEM imaging was performed at $2 \mathrm{kV}$ and $13 \mathrm{pA}$, whereas FIB imaging for targeting was performed at $30 \mathrm{kV}$ and $10 \mathrm{pA}$. Milling was typically performed with a stage tilt of $18^{\circ}$, so lamellae were inclined $11^{\circ}$ relative to the grid. Each lamella was milled in four stages: an initial rough mill at $1 \mathrm{nA}$ beam current, an intermediate mill at $300 \mathrm{pA}$, a fine mill at $100 \mathrm{pA}$, and a polishing step at 30 pA. Lamellae were milled with the wedge pre-milling technique described in (Schaffer et al., 2017) and with expansion segments as described in (Wolff et al., 2019).

Tilt series acquisition. Tilt series were acquired on either a Talos Arctica (ThermoFisher) operating at $200 \mathrm{kV}$ or a Titan Krios (ThermoFisher) operating at $300 \mathrm{kV}$, both equipped with a post-column energy filter (Gatan) in zeroloss imaging mode with a $20-\mathrm{eV}$ energy-selecting slit. All images were recorded on a K2 Summit direct electron detector (Gatan) in either counting or super-resolution mode with dose-fractionation. Tilt series were collected using SerialEM (Mastronarde, 2005) at a target defocus of between -4 and -6 $\mu \mathrm{m}$ (conventional defocus-contrast) or between -0.5 and -1.5 $\mu \mathrm{m}$ (for tilt series acquired with the Volta phase plate). Tilt series were typically recorded using either strict or grouped dose-symmetric schemes, either spanning $\pm 56^{\circ}$ in $2^{\circ}$ increments or $\pm 54^{\circ}$ in $3^{\circ}$ increments, with total dose limited to $\sim 100 e^{-} / \AA^{2}$. 
Tomogram reconstruction. Frames were aligned either post-acquisition using Motioncor2 1.2.1 (Zheng et al., 2017) or on-the-fly using Warp (Tegunov and Cramer, 2019). Frames were usually collected in counting mode; when super-resolution frames were used, they were binned $2 \mathrm{X}$ during motion correction. Tomograms were reconstructed in IMOD (Kremer et al., 1996) using weighted back-projection, with a SIRT-like filter (Zeng, 2012) applied for visualization and segmentation. Defocus-contrast tomograms were CTFcorrected in IMOD using ctfphaseflip while VPP tomograms were left uncorrected.

Tomogram segmentation. Tomogram segmentation was generally performed semi-automatically. Initial segmentation was performed using the neural network-based TomoSeg package in EMAN 2.21. Segmentation was then refined manually in either Avizo 9.2.0 (FEI) or Chimera 1.12. Membrane distance measurements were performed using built-in functions in Avizo 9.2.0.

Subtomogram averaging of crystalloid patches. Subtomogram averaging with missing wedge compensation was performed using PEET 1.13.0 (Heumann et al., 2011; Nicastro et al., 2006). Alignments were performed first on $4 \mathrm{x}-$ binned defocus-contrast tomograms, after which aligned positions and orientations were transferred to $2 \mathrm{x}$-binned data using scripts shared by Dr. Daven Vasishtan.

Particle positions were seeded by generating a threedimensional grid of points in crystalloid patches using the gridInit program. All particle orientations were randomized and initial alignments allowed for full rotational searches around all axes. To ensure consistency, two independent initial alignments were performed, each using a randomlyselected particle from a separate tomogram as an initial reference. Since alignments converged on a similar structure, alignments were continued. The dataset was cleaned by (i) removing all particles with a cross-correlation value less than one standard deviation above the mean (which removed poorly-aligning particles such as those at the edges of crystalloid patches) and by (ii) removing overlapping particles. The orientations of the remaining particles were again randomized and another alignment performed. After a final particle clean-up by classification, a final restricted alignment run was performed. Averages presented in the manuscript were filtered to the estimated resolution based on the Fourier shell correlation (FSC) at a cut-off of 0.5 (Nicastro et al., 2006).

Measurements and quantification. All measurements were performed on $\sim 20$-nm thick central tomographic slices. Acrosomal width was measured manually in IMOD as the distance between the outer and inner acrosomal membranes. For each tomogram, three measurements were recorded at different locations to account for slight variations in the shape of the acrosome. Linescans for measurement of the postacrosomal sheath were performed in Fiji v 2.0.0-rc-69/1.52p.

Data availability. Subtomogram average maps will be deposited to the Electron Microscopy Data Bank (EMDB). 
bioRxiv preprint doi: https://doi.org/10.1101/2021.08.04.455016; this version posted August 5, 2021. The copyright holder for this preprint (which was not certified by peer review) is the author/funder, who has granted bioRxiv a license to display the preprint in perpetuity. It is made available under aCC-BY-NC-ND 4.0 International license.
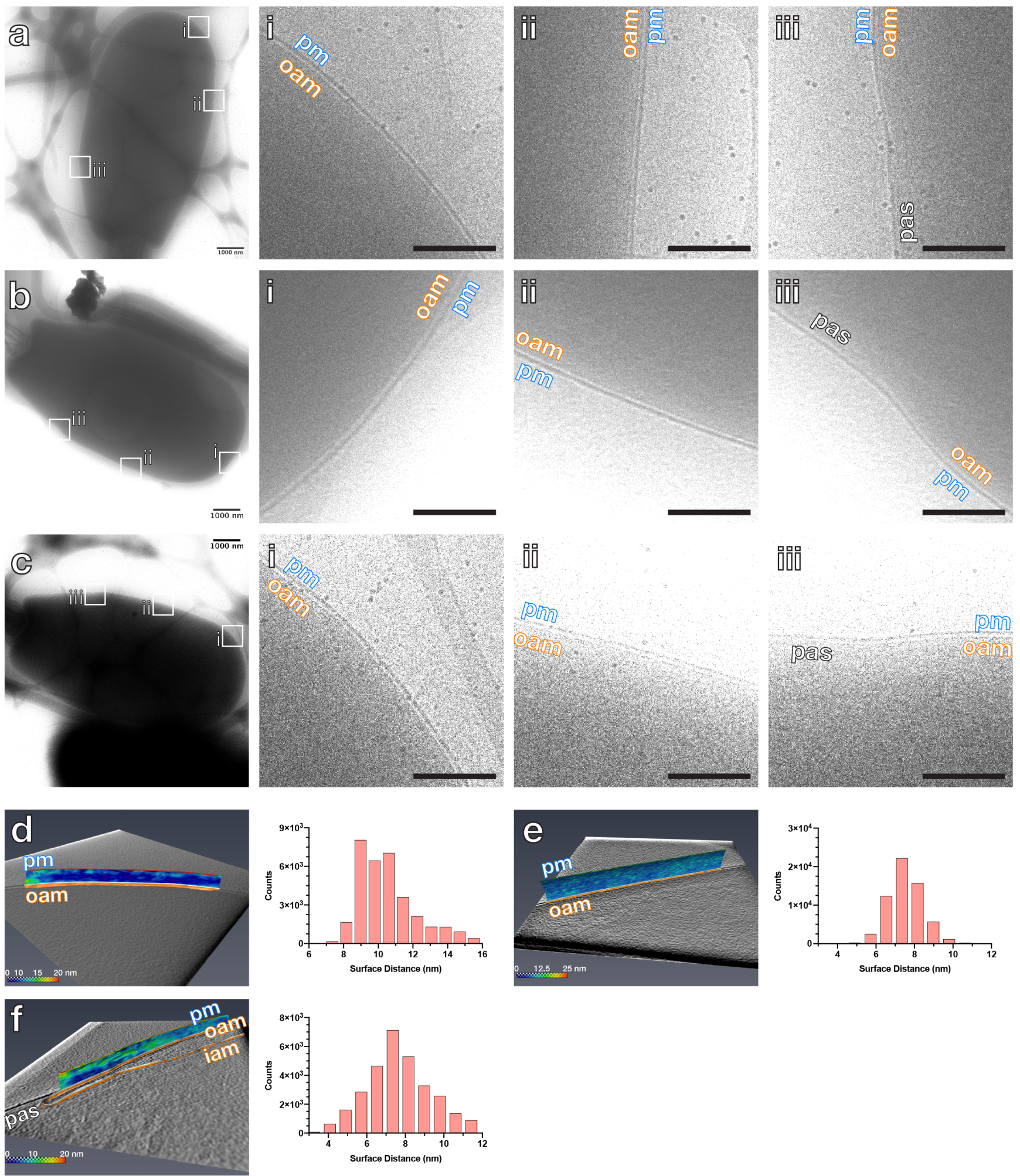

Fig. S1. The plasma membrane and the outer acrosomal membrane are closely spaced even in non-capacitated sperm. (a-c) Low-magnification high-dose cryo-EM projection images of non-capacitated boar sperm heads. Digital zooms show close apposition between the plasma membrane and the outer acrosomal membrane at the apical (i), pre-equatorial (ii), and equatorial (iii) regions. (d-f) Left panels show three-dimensional segmentations of the plasma membrane and the outer acrosomal membrane at the apical (d), pre-equatorial (e), and equatorial (f) regions. The plasma membrane is colored based on distance from the outer acrosomal membrane, which is shown as a cutaway view in orange. Right panels show corresponding histograms of intermembrane distances. Scale bars: (a-c) $1 \mu \mathrm{m}$; digital zooms: $250 \mathrm{~nm}$. Labels: pm - plasma membrane, oam - outer acrosomal membrane, pas - post-acrosomal sheath 

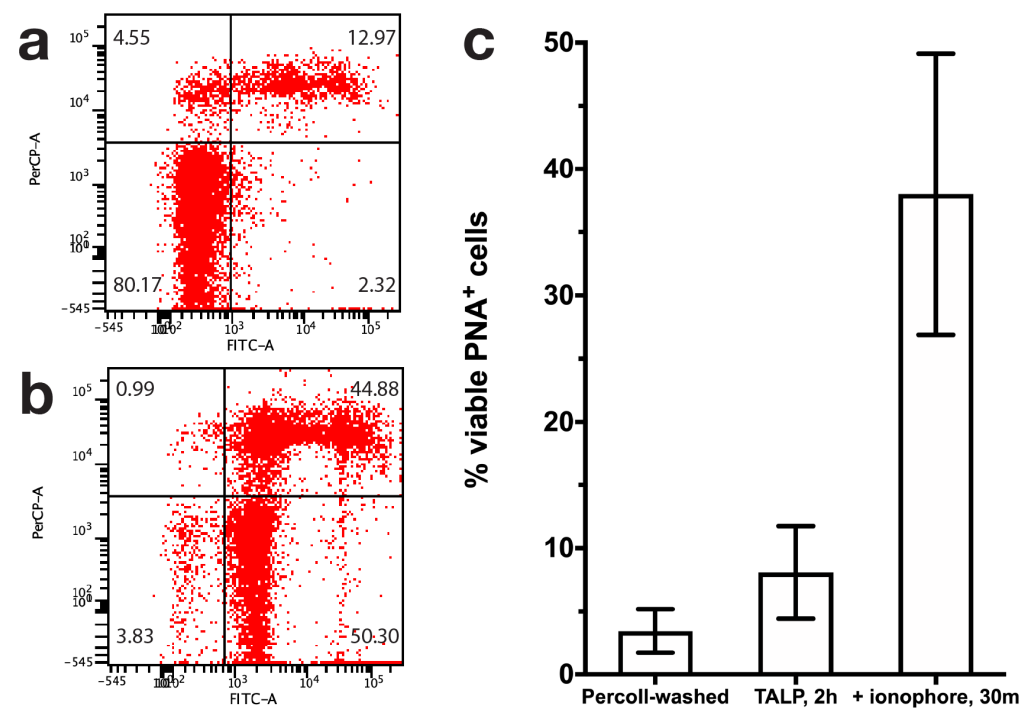

Fig. S2. Flow-cytometric assessment of acrosome reaction efficiency. (a-b) Flow cytograms of non-capacitated sperm (a) and sperm stimulated to acrosome react with ionophore A23187 (b). (c) Proportion of viable acrosome-reacted sperm (PI-, PNA-FITC+) as assessed by flow cytometry. Bar graphs show mean \pm standard deviation and summarize three independent experiments on three separate animals. 

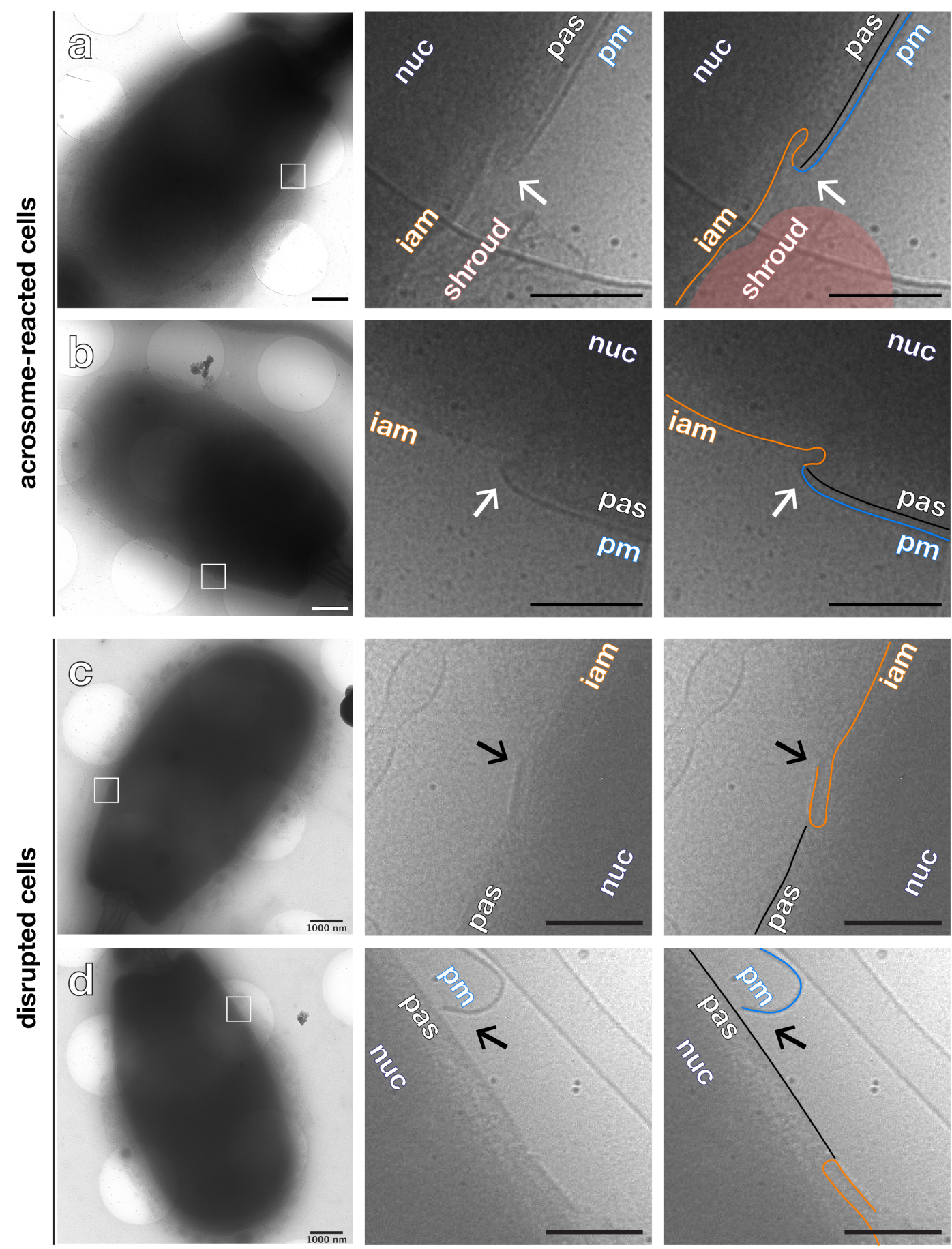

Fig. S3. Distinguishing acrosome-reacted sperm from membrane-disrupted sperm in low-magnification cryo-EM projection images. Low-magnification high-dose cryo-EM projection images of acrosome-reacted (a-b) and membrane-disrupted (c-d) sperm. Note how acrosome-reacted sperm successfully re-seal at the equatorial/post-acrosomal region (a-b, white arrows in digital zooms); in contrast, membrane-disrupted sperm have also lost the plasma membrane overlying the post-acrosomal sheath (c-d, black arrows in digital zooms). Also note how the apical region becomes very thin in acrosome-reacted cells; in contrast, membrane-disrupted sperm retain an acrosomal ghost around their heads. Scale bars: (a-d) $1 \mu \mathrm{m}$; digital zooms: $250 \mathrm{~nm}$. Labels: pm - plasma membrane, oam - outer acrosomal membrane, iam - inner acrosomal membrane, pas - post-acrosomal sheath, nuc - nucleus, shroud - acrosomal shroud. Color scheme: blue - plasma membrane, orange - inner acrosomal membrane, black - post-acrosomal sheath, red acrosomal shroud. 
bioRxiv preprint doi: https://doi.org/10.1101/2021.08.04.455016; this version posted August 5, 2021. The copyright holder for this preprint (which was not certified by peer review) is the author/funder, who has granted bioRxiv a license to display the preprint in perpetuity. It is made available under aCC-BY-NC-ND 4.0 International license.
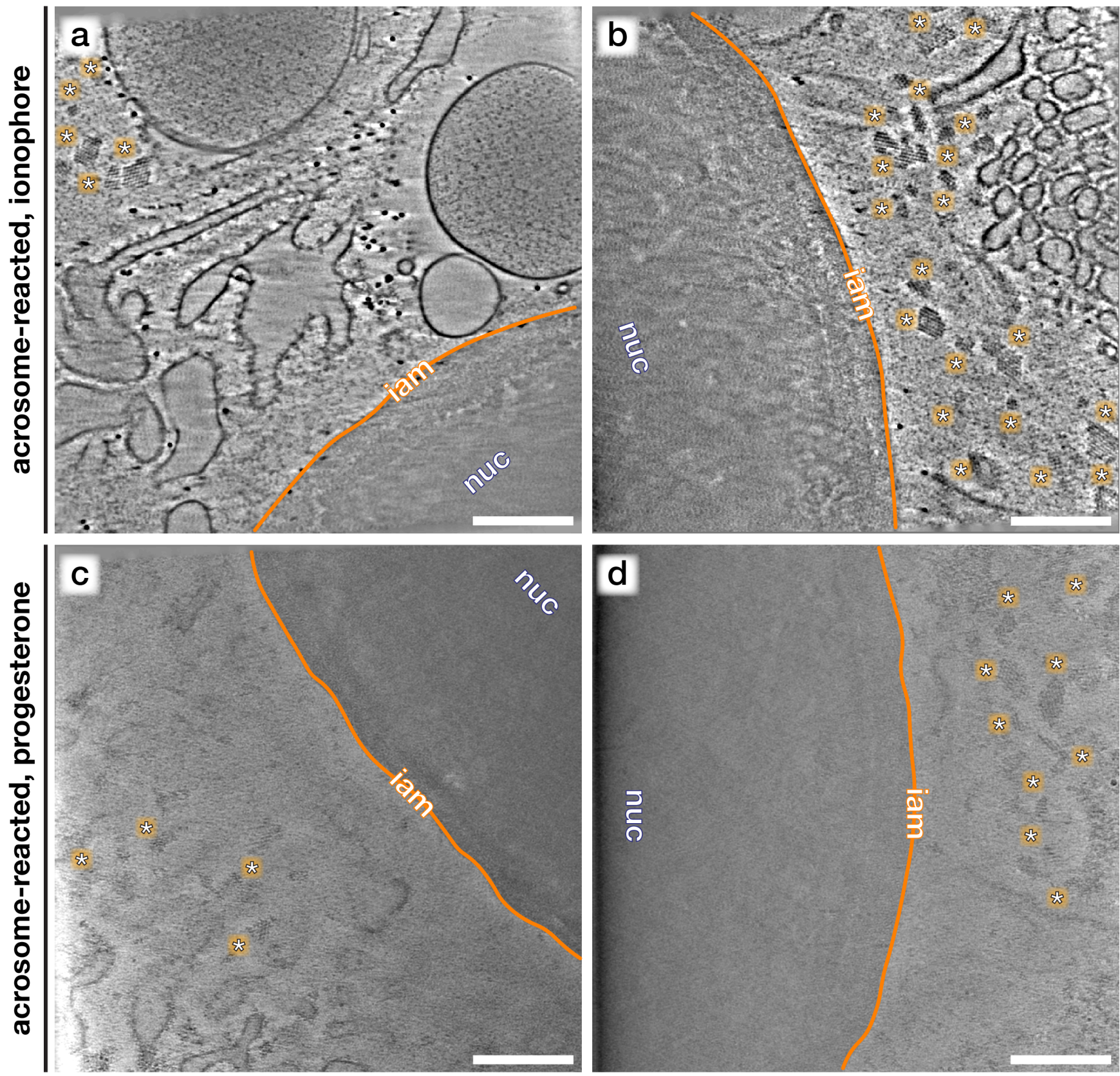

Fig. S4. Additional examples of crystalloid patches in the acrosomal shroud of acrosome-reacted cells. Computational slices through Volta phase plate cryo-tomograms of the acrosomal shroud collected at the apical region of sperm stimulated to undergo acrosomal exocytosis with either calcium ionophore $(\mathbf{a}, \mathbf{b})$ or progesterone $(\mathbf{c}, \mathbf{d})$. Note the presence of crystalloid patches $($ asterisks) of varying shapes and sizes in all tomograms. Scale bars: $250 \mathrm{~nm}$. Labels: iam - inner acrosomal membrane, nuc - nucleus. 
acrosome swelling/decondensation
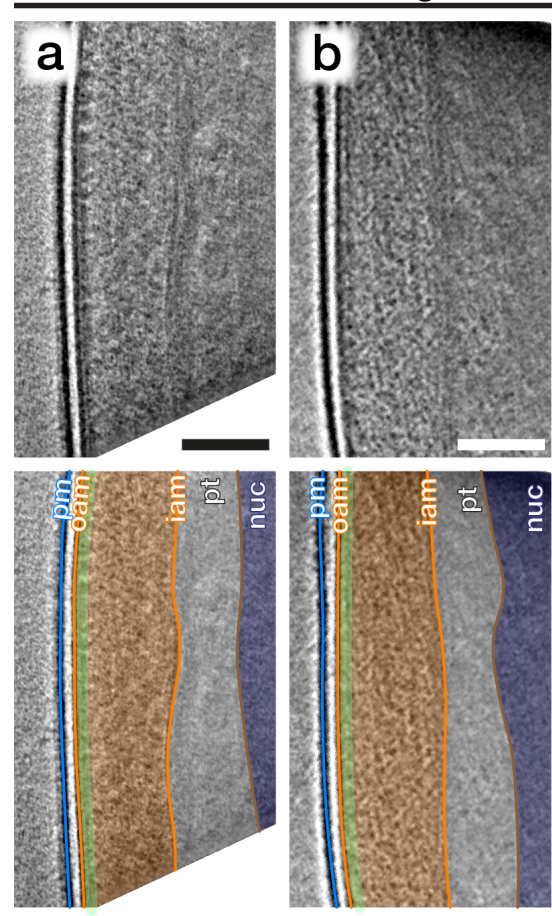
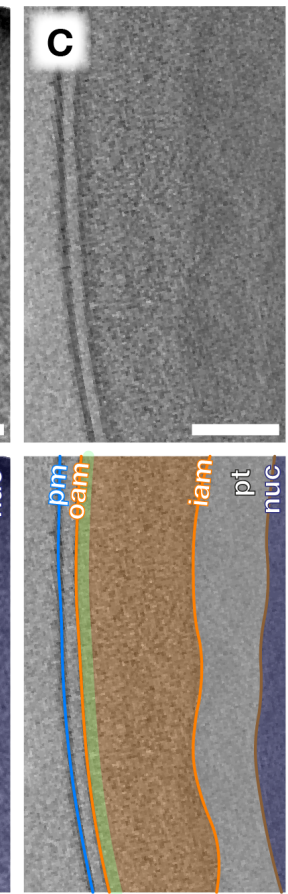

membrane destabilization

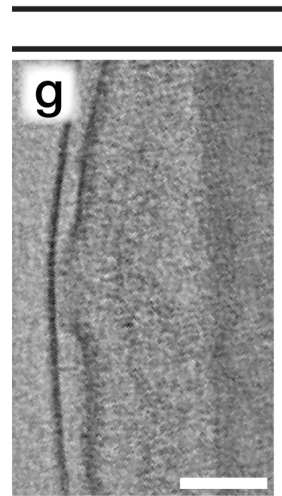

pre-equatorial
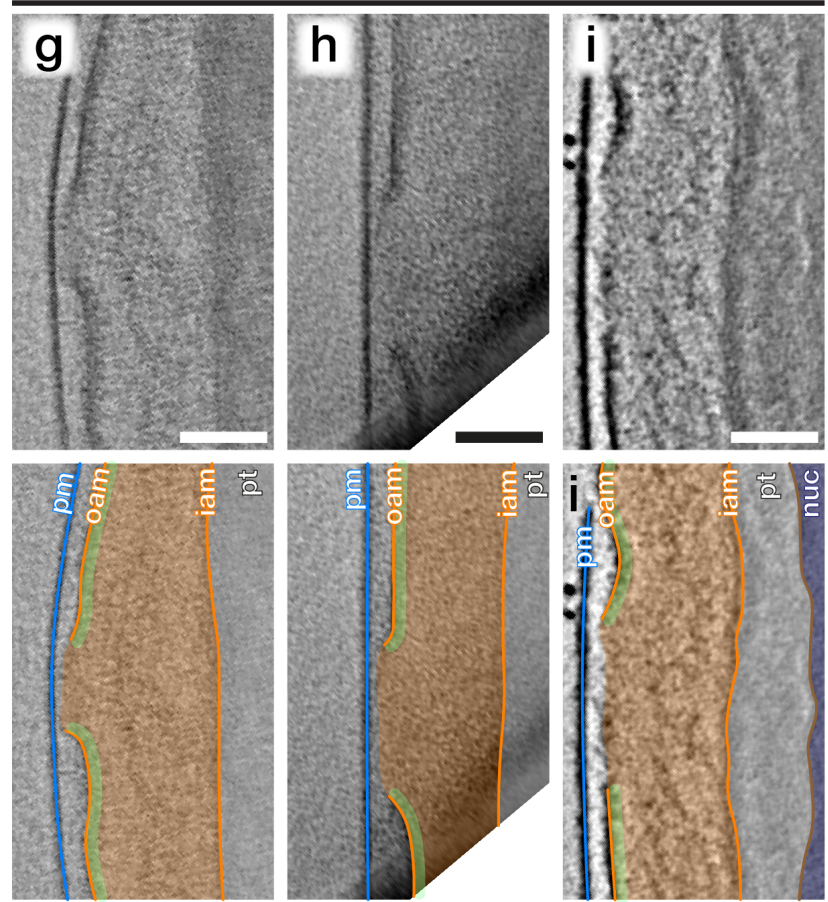

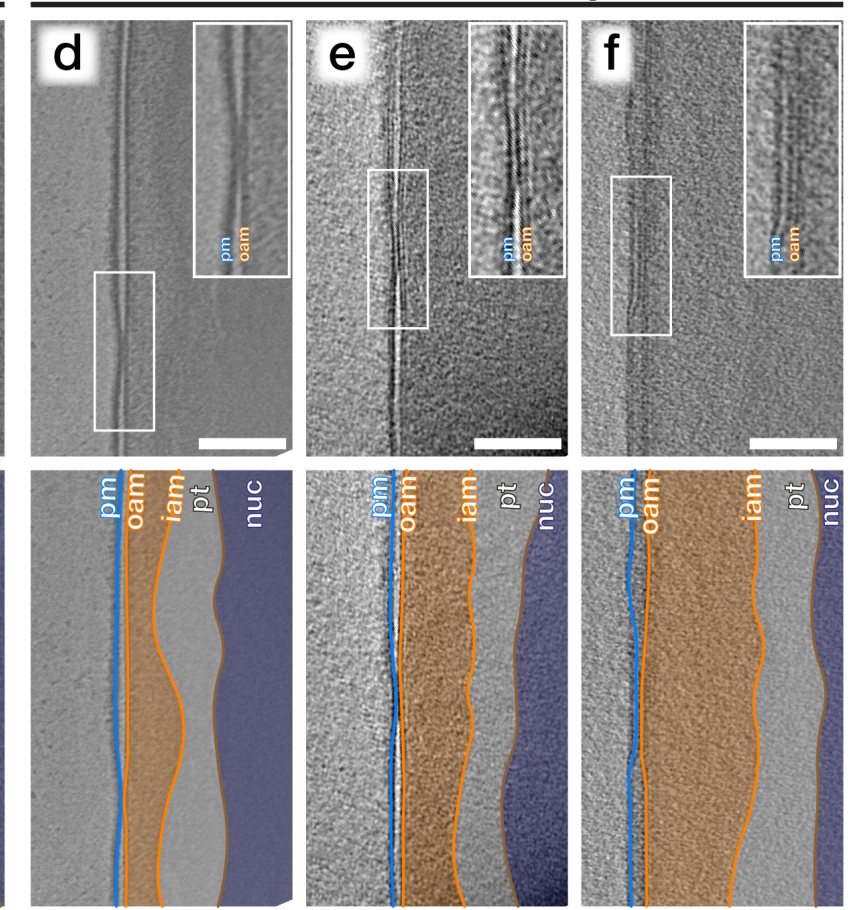

membrane docking

equatorial
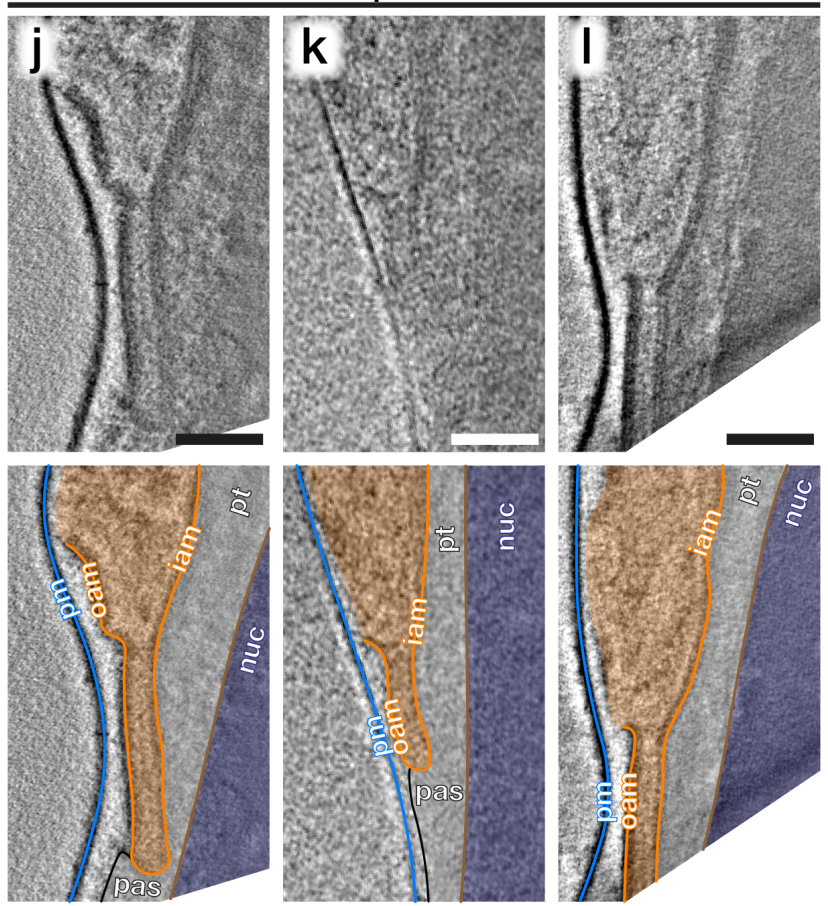

Fig. S5. Additional examples of membrane remodelling intermediates observed in sperm incubated in capacitating media without ionophore stimulation. Computational slices through cryo-tomograms of sperm with (a-c) swollen acrosomes and intact membranes; (d-f) swollen acrosomes and locally-docked membranes (insets); and (g-l) profusely-swollen acrosomes and destabilized membranes at the pre-equatorial ( $g-i)$ and equatorial regions (j-l). Tomograms in (a), (b), (d), (i), (j), and (l) were acquired with the Volta phase plate while tomograms in (c), (e), (f), (g), (h), and (k) were acquired with defocus-contrast. Scale bars: $100 \mathrm{~nm}$. Labels: pm plasma membrane, oam - outer acrosomal membrane, iam - inner acrosomal membrane, pt - perinuclear theca, pas - post-acrosomal sheath, nuc - nucleus. Color scheme: blue - plasma membrane, orange - outer and inner acrosomal membranes, green - membrane protein densities, grey - perinuclear theca and post-acrosomal sheath, brown - nuclear envelope, dark blue - nucleus. 
bioRxiv preprint doi: https://doi.org/10.1101/2021.08.04.455016; this version posted August 5, 2021. The copyright holder for this preprint (which was not certified by peer review) is the author/funder, who has granted bioRxiv a license to display the preprint in perpetuity. It is made available under aCC-BY-NC-ND 4.0 International license.
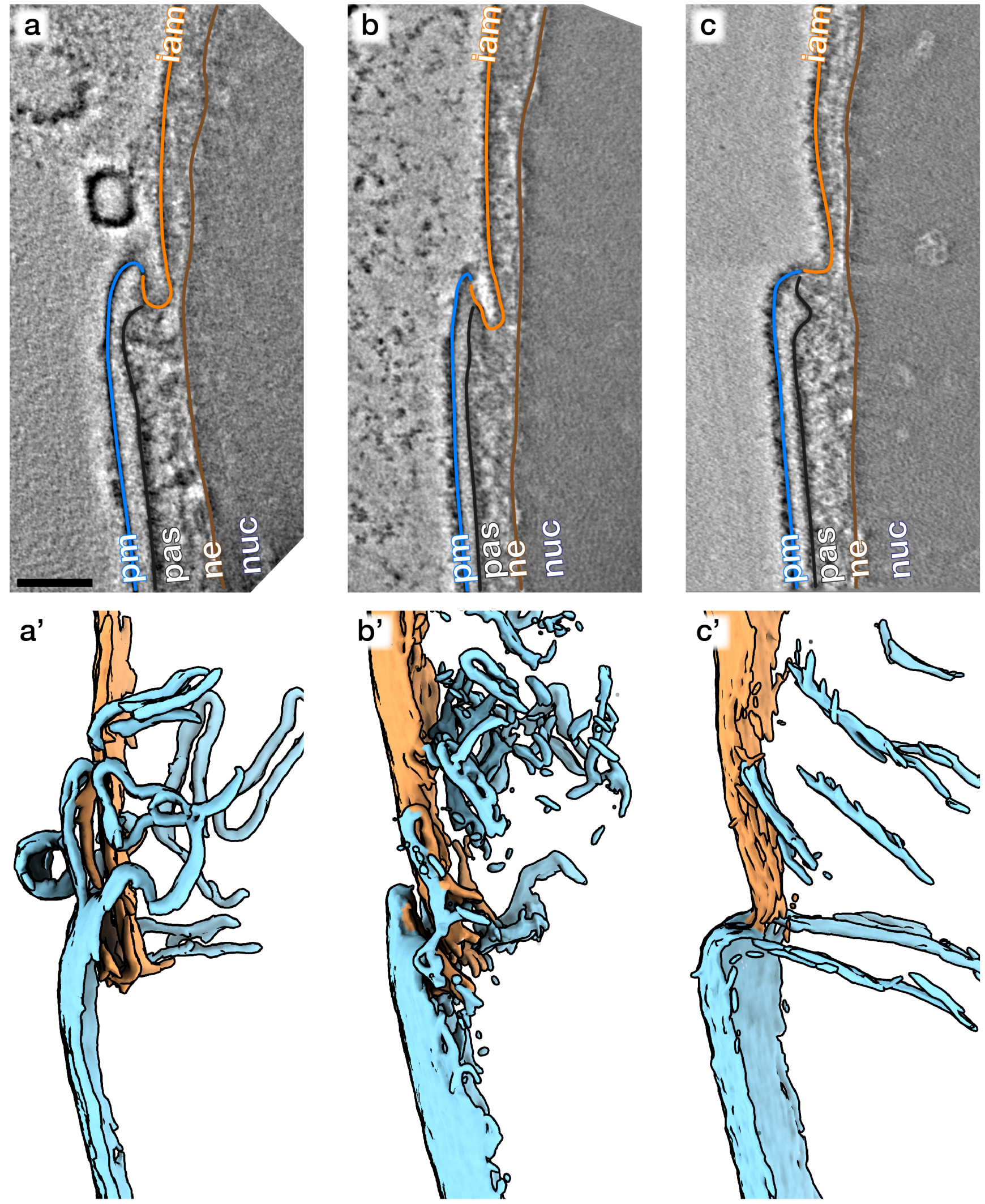

Fig. S6. Additional examples of the remodelled topography of acrosome-reacted cells. (a-c) Computational slices and (a'-c') corresponding three-dimensional segmentations of Volta phase plate cryo-tomograms of acrosome-reacted sperm. Scale bars: 250 nm. Labels: pm - plasma membrane, iam - inner acrosomal membrane, pas - post-acrosomal sheath, ne - nuclear envelope, nuc - nucleus. Color scheme: blue - plasma membrane, orange - inner acrosomal membrane, black - post-acrosomal sheath, brown nuclear envelope 
bioRxiv preprint doi: https://doi.org/10.1101/2021.08.04.455016; this version posted August 5, 2021. The copyright holder for this preprint (which was not certified by peer review) is the author/funder, who has granted bioRxiv a license to display the preprint in perpetuity. It is made available under aCC-BY-NC-ND 4.0 International license.
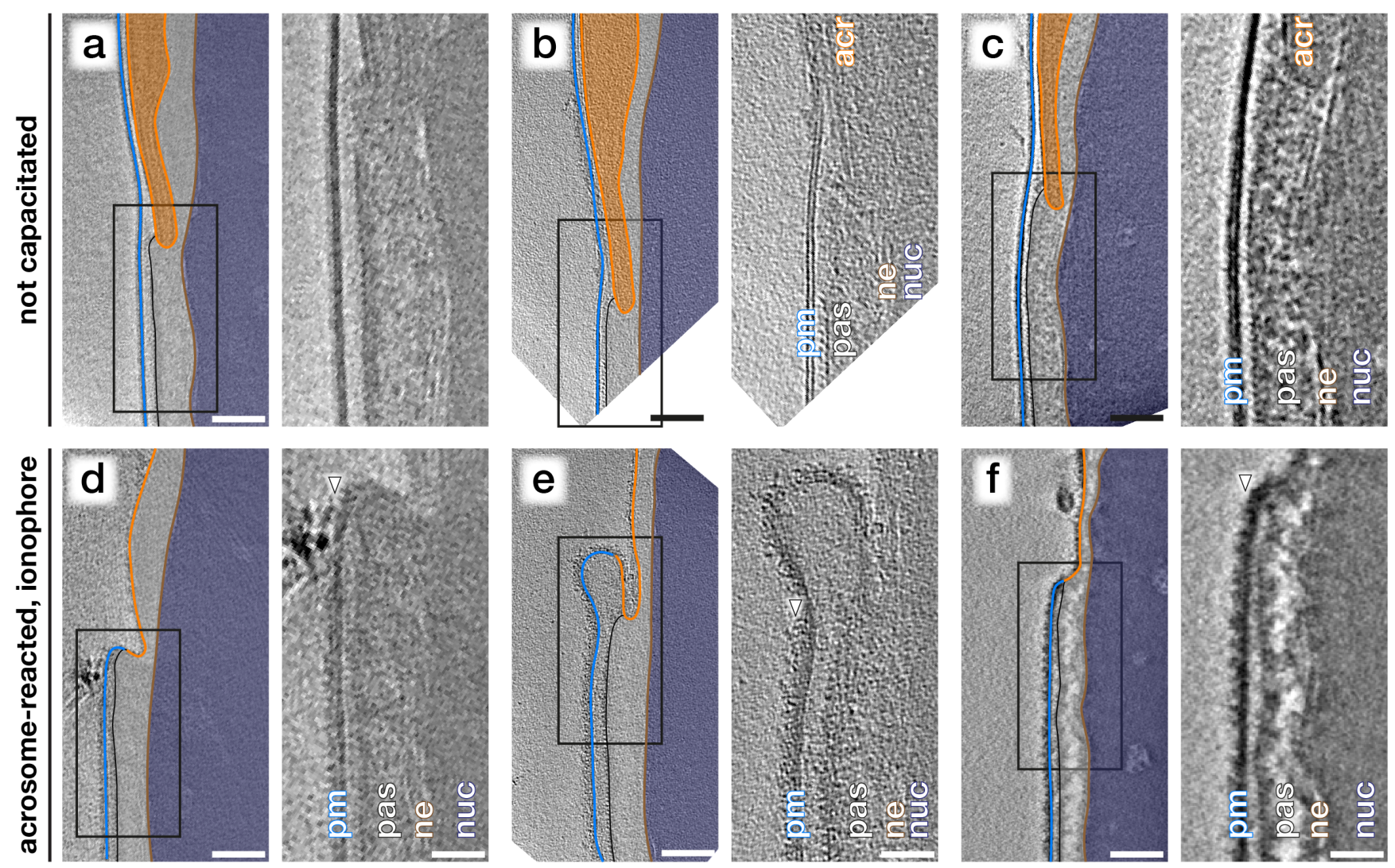

Fig. S7. Additional examples of membrane protein relocalization onto the post-acrosomal plasma membrane of acrosome reacted cells. Computational slices through cryo-tomograms of the equatorial/post-acrosomal region in unstimulated, non-capacitated (a-c) and acrosome-reacted (d-f) sperm. The change in membrane protein decoration (arrowheads in d-f) is seen consistently even in three different imaging conditions: intermediate-magnification defocus contrast (a,d), high-magnification defocus contrast (b,e), and high-magnification Volta phase plate contrast (c,f). Scale bars: $100 \mathrm{~nm}$. Labels: pm - plasma membrane, iam - inner acrosomal membrane, pas - post-acrosomal sheath, ne - nuclear envelope, nuc - nucleus. Color scheme: blue - plasma membrane, orange inner acrosomal membrane, black - post-acrosomal sheath, brown - nuclear envelope 
Table S1. Dataset summary reporting number of tomograms in the dataset representing each membrane remodelling intermediate.

\section{description}

\begin{tabular}{lccc}
\hline \multirow{2}{*}{ description } & \multicolumn{3}{c}{ condition } \\
\cline { 2 - 4 } & unstimulated & capacitated & acrosome-reacted \\
\hline dense acrosome, membranes intact & 26 & 10 & - \\
swollen acrosome, membranes intact & - & 15 & - \\
swollen acrosome, membranes destabilized & - & 16 & - \\
acrosome-reacted, apical region, shroud present & - & - & 13 (ionophore), 5 (progesterone) \\
acrosome-reacted, apical region, shroud absent & - & - & 6 (ionophore) \\
acrosome-reacted, equatorial region & - & - & 37 (ionophore) \\
\hline total number of tomograms & $\mathbf{2 6}$ & $\mathbf{4 1}$ & $\mathbf{5 6}$ (ionophore), $\mathbf{5}$ (progesterone) \\
total number of animals & $\mathbf{7}$ & $\mathbf{5}$ & $\mathbf{6}$ (ionophore), $\mathbf{1}$ (progesterone) \\
\hline
\end{tabular}


bioRxiv preprint doi: https://doi.org/10.1101/2021.08.04.455016; this version posted August 5, 2021. The copyright holder for this preprint (which was not certified by peer review) is the author/funder, who has granted bioRxiv a license to display the preprint in perpetuity. It is made available under aCC-BY-NC-ND 4.0 International license.

\section{${ }_{571}$ References} Med. 56, 334-348. C1-5 147-157. 143-154. $1645-1650$. J. $275,759-766$.
Aguas, A.P., and da Silva, P.P. (1989). Bimodal redistribution of surface transmem- 656 brane glycoproteins during Ca2+-dependent secretion (acrosome reaction) in boar ${ }^{657}$ spermatozoa. J. Cell Sci. 93 ( Pt 3), 467-479.

Aitken, R.J., and Nixon, B. (2013). Sperm capacitation: A distant landscape 660 glimpsed but unexplored. Mol. Hum. Reprod. 19, 785-793. 661

Asano, A., Nelson-Harrington, J.L., and Travis, A.J. (2013). Phospholipase B is 663 activated in response to sterol removal and stimulates acrosome exocytosis in 664 murine sperm. J. Biol. Chem. 288, 28104-28115.

Austin, C. (1951). Observations on the Penetration of the Sperm into the Mammalian Egg. Aust. J. Biol. Sci. 4, 581.

Bailey, J.L. (2010). Factors regulating sperm capacitation. Syst. Biol. Reprod. 670

Barros, C., Bedford, J.M., Franklin, L.E., and Austin, C.R. (1967). Membrane ${ }^{673}$ vesiculation as a feature of the mammalian acrosome reaction. J. Cell Biol. 34, 675

Bielfeld, P., Jeyendran R.S., and Zaneveld, L.J.D. (1993). Osmo-sensitivity of the 677 human sperm acrosome reaction. Hum. Reprod. 8, 1235-1239.

Boerke, A., van der Lit, J., Lolicato, F., Stout, T.A.E., Helms, J.B., and Gadella, B. (2014). Removal of GPI-anchored membrane proteins causes clustering of lipid mi- 682 crodomains in the apical head area of porcine sperm. Theriogenology 81, 613-624. 683

Buffone, M.G., Foster, J.A., and Gerton, G.L. (2008). The role of the acrosomal ${ }_{685}^{684}$ matrix in fertilization. Int. J. Dev. Biol. 52, 511-522.

Buffone, M.G., Hirohashi, N., and Gerton, G.L. (2014). Unresolved Questions 688 Concerning Mammalian Sperm Acrosomal Exocytosis. Biol. Reprod. 90, 1-8.

Chang M.C. (1951). Fertilizing capacity of spermatozoa deposited into the 690 fallopian tubes. Nature 168, 697-698.

Chang, M.C. (1959). Fertilization of rabbit ova in vitro. Nature 184, 466-467.

Chlanda, P., Mekhedov, E., Waters, H., Schwartz, C.L., Fischer, E.R., Ryham, R.J., 696 Cohen, F.S., Blank, P.S., and Zimmerberg, J. (2016). The hemifusion structure 697 induced by influenza virus haemagglutinin is determined by physical properties of 698 the target membranes. Nat. Microbiol. 1, 16050.

Danev, R., Buijsse, B., Khoshouei, M., Plitzko, J.M., and Baumeister, W. (2014). ${ }^{701}$ Volta potential phase plate for in-focus phase contrast transmission electron ${ }^{702}$ microscopy. Proc. Natl. Acad. Sci. U. S. A. 111, 15635-15640.

Flaherty, S.P., and Olson, G.E. (1991). Ultrastructural analysis of the acrosome ${ }^{705}$ reaction in a population of single guinea pig sperm. Anat. Rec. 229, 186-194. 706

Fléchon, J.-E. (2016). The acrosome of eutherian mammals. Cell Tissue Res. 363, ${ }_{709}^{708}$

Foster, J.A., and Gerton, G.L. (2016). The Acrosomal Matrix. In Advances in $\begin{aligned} & 711 \\ & 712\end{aligned}$ Anatomy, Embryology, and Cell Biology, pp. 15-33.

Fukuda, Y., Laugks, U., Lučić, V., Baumeister, W., and Danev, R. (2015). Electron $\begin{aligned} & 714 \\ & 715\end{aligned}$ cryotomography of vitrified cells with a Volta phase plate. J. Struct. Biol. 190, 716

Gervasi, M.G., and Visconti, P.E. (2016). Chang's meaning of capacitation: $A_{719}^{718}$ molecular perspective. Mol. Reprod. Dev. 83, 860-874.

Glushakova, S., Yin, D., Li, T., and Zimmerberg, J. (2005). Membrane Transformation during Malaria Parasite Release from Human Red Blood Cells. Curr. Biol. 15,

Haldar, S., Mekhedov, E., McCormick, C.D., Blank, P.S., and Zimmerberg, J. (2019). Lipid-dependence of target membrane stability during influenza viral fusion. J. Cell Sci. 132, jcs218321.

Hardy, D.M., Oda, M.N., Friend, D.S., and Huang, T.T.F. (1991). A mechanism for differential release of acrosomal enzymes during the acrosome reaction. Biochem.

Harrison, R.A.P., and Gadella, B.M. (2005). Bicarbonate-induced membrane processing in sperm capacitation. Theriogenology 63, 342-351.

Jamil, K., and White, I.G. (1981). Induction of Acrosomal Reaction in Sperm with lonophore A23187 and Calcium. Arch. Androl. 7, 283-292.
Kim, K.-S., and Gerton, G.L. (2003). Differential release of soluble and matrix components: evidence for intermediate states of secretion during spontaneous acrosomal exocytosis in mouse sperm. Dev. Biol. 264, 141-152.

Kim, K.-S., Foster, J.A., and Gerton, G.L. (2001). Differential Release of Guinea Pig Sperm Acrosomal Components During Exocytosis1. Biol. Reprod. 64, 148-156.

de Lamirande, E., Leclerc, P., and Gagnon, C. (1997). Capacitation as a regulatory event that primes spermatozoa for the acrosome reaction and fertilization. Mol. Hum. Reprod. 3, 175-194.

Marko, M., Hsieh, C., Moberlychan, W., Mannella, C.A., and Frank, J. (2006) Focused ion beam milling of vitreous water: Prospects for an alternative to cryo-ultramicrotomy of frozen-hydrated biological samples. J. Microsc. 222, 42-47.

Nagae, T., Yanagimachi, R., Srivastava, P.N., and Yanagimachi, H. (1986). Acrosome reaction in human spermatozoa. Fertil. Steril. 45, 701-707.

$\mathrm{Ng}$, C.T., and Gan, L. (2020). Investigating eukaryotic cells with cryo-ET. Mol. Biol. Cell 31, 87-100.

Nolan, J.P., and Hammerstedt, R.H. (1997). Regulation of membrane stability and the acrosome reaction in mammalian sperm. FASEB J. 11, 670-682.

Olson, G.E., and Winfrey, V.P. (1994). Structure of Acrosomal Matrix Domains of Rabbit Sperm. J. Struct. Biol. 112, 41-48.

Parrish, J.J., Susko-Parrish, J., Winer, M.A., and First, N.L. (1988). Capacitation of bovine sperm by heparin. Biol. Reprod. 38, 1171-1180.

Phillips, D.M. (1972). Substructure of the mammalian acrosome. J. Ultrasructure Res. 38, 591-604

Rigort, A., Bauerlein, F.J.B., Villa, E., Eibauer, M., Laugks, T., Baumeister, W., and Plitzko, J.M. (2012). Focused ion beam micromachining of eukaryotic cells for cryoelectron tomography. Proc. Natl. Acad. Sci. 109, 4449-4454.

Russell, L., Peterson, R., and Freund, M. (1979). Direct evidence for formation of hybrid vesicles by fusion of plasma and outer acrosomal membranes during the acrosome reaction in boar spermatozoa. J. Exp. Zool. 208, 41-55.

Sosa, C.M., Pavarotti, M.A., Zanetti, M.N., Zoppino, F.C.M., De Blas, G.A., and Mayorga, L.S. (2015). Kinetics of human sperm acrosomal exocytosis. Mol. Hum. Reprod. 21, 244-254.

Stock, C.E., and Fraser, L.R. (1987). The acrosome reaction in human sperm from men of proven fertility. Hum. Reprod. 2, 109-119.

Travis, A.J., and Kopf, G.S. (2002). The role of cholesterol efflux in regulating the fertilization potential of mammalian spermatozoa. J. Clin. Invest. 110, 731-736.

Tsai, P.-S.S., Garcia-Gil, N., van Haeften, T., and Gadella, B.M. (2010). How pig sperm prepares to fertilize: stable acrosome docking to the plasma membrane. PLoS One 5 .

Yanagimachi, R. (1981). Mechanisms of Fertilization in Mammals. In Fertilization and Embryonic Development In Vitro, L. Mastroianni, and J.D. Biggers, eds. (Boston, MA: Springer), pp. 81-182.

Yudin, A.I., Gottlieb, W., and Meizel, S. (1988). Ultrastructural studies of the early events of the human sperm acrosome reaction as initiated by human follicular fluid. Gamete Res. 20, 11-24.

Zanetti, N., and Mayorga, L.S. (2009). Acrosomal Swelling and Membrane Docking Are Required for Hybrid Vesicle Formation During the Human Sperm Acrosome Reaction. Biol. Reprod. 81, 396-405. 